\title{
Genome-wide survey and expression analysis of calcium-dependent protein kinase (CDPK) in grass Brachypodium distachyon
}

Feng Wen ${ }^{*}$, Feng $\mathrm{Ye}^{\dagger}$, Zhulong Xiao ${ }^{\dagger}$, Liang Liao, Tongjian Li, Mingliang Jia, Xinsheng Liu and Xiaozhu Wu ${ }^{*}$

\begin{abstract}
Background: $\mathrm{Ca}^{2+}$ played as a ubiquitous secondary messenger involved in plant growth, development, and responses to various environmental stimuli. Calcium-dependent protein kinases (CDPK) were important $\mathrm{Ca}^{2+}$ sensors, which could directly translate $\mathrm{Ca}^{2+}$ signals into downstream phosphorylation signals. Considering the importance of CDPKs as $\mathrm{Ca}^{2+}$ effectors for regulation of plant stress tolerance and few studies on Brachypodium distachyon were available, it was of interest for us to isolate CDPKs from B. distachyon.

Results: A systemic analysis of 30 CDPK family genes in B. distachyon was performed. Results showed that all BdCDPK family members contained conserved catalytic Ser/Thr protein kinase domain, autoinhibitory domain, and EF-hand domain, and a variable N-terminal domain, could be divided into four subgroup (I-IV), based upon sequence homology. Most BdCDPKs had four EF-hands, in which EF2 and EF4 revealed high variability and strong divergence from EF-hand in AtCDPKs. Synteny results indicated that large number of syntenic relationship events existed between rice and B. distachyon, implying their high conservation. Expression profiles indicated that most of $B d C D P K$ genes were involved in phytohormones signal transduction pathways and regulated physiological process in responding to multiple environmental stresses. Moreover, the co-expression network implied that BdCDPKs might be both the activator and the repressor involved in WRKY transcription factors or MAPK cascade genes mediated stress response processes, base on their complex regulatory network.

Conclusions: BdCDPKs might play multiple function in WRKY or MAPK mediated abiotic stresses response and phytohormone signaling transduction in B. distachyon. Our genomics analysis of BdCDPKs could provide fundamental information for further investigation the functions of CDPKs in integrating $\mathrm{Ca}^{2+}$ signalling pathways in response to environments stresses in B. distachyon.
\end{abstract}

Keywords: CDPK, Phytohormones, Abiotic stresses, Expression pattern, Brachypodium distachyon

\section{Background}

To adapt the environmental stresses, such as drought, cold, heat and high salinity, plant developed a series of effective defense mechanism comprised of stress signal perception and subsequent transduction, leading to the activation of various physiological and metabolic responses [1]. As a ubiquitous secondary messenger, $\mathrm{Ca}^{2+}$ played an important role in the signal transduction

\footnotetext{
*Correspondence: wenfeng332@126.com; wuxiaozhu3@gmail.com

${ }^{\dagger}$ Feng Wen, Feng Ye and Zhulong Xiao contributed equally to this work. School of Pharmacy and Life Science, Jiujiang University, Jiujiang, China
}

pathways via transiently changing in the cytoplasmic $\mathrm{Ca}^{2+}$ concentration in plant growth and development, as well as responses to various environmental stimuli [24]. During exposure of plants to stress, several $\mathrm{Ca}^{2+}$ sensors or $\mathrm{Ca}^{2+}$ binding proteins can sense $\mathrm{Ca}^{2+}$ concentration changes and recognize the $\mathrm{Ca}^{2+}$ signatures, and then subsequently transduct them into a series of downstream effects to improve plant resistance $[5,6]$. Up to present, four major classes of $\mathrm{Ca}^{2+}$ sensors or $\mathrm{Ca}^{2+}$ binding proteins, including calmodulins $(\mathrm{CaM})$, calmodulinlike proteins $(\mathrm{CaML})$, calcineurin B-like proteins $(\mathrm{CBL})$ 
and calcium-dependent protein kinases (CDPK), have been indentified in plants [7-10]. Among these, CDPKs were distinctive because their unique structure, which contains a catalytic Ser/Thr protein kinase domain and a CaM domain containing EF-hand motifs for $\mathrm{Ca}^{2+}$-binding capacity [11]. Therefore, CDPK proteins can function both as $\mathrm{Ca}^{2+}$ sensors and effectors to directly translate $\mathrm{Ca}^{2+}$ signals into downstream phosphorylation signals $[12,13]$.

CDPKs, which were plant-specific gene family, have been identified throughout the plant kingdom, but not in animals $[6,14,15]$. Typical CDPK gene family members were composed of four conserved domains, including a variable $\mathrm{N}$-terminal domain, a protein kinase domain, an auto-inhibitory domain and a C-terminal regulatory calmodulin-like domain [6]. The N-terminal domains were consisting of the myristoylation and palmitoylation sites, which helped CDPKs anchor to or/and dissociate from membranes, which were highest sequence divergence among CDPKs [16]. The different lengths and amino acid compositions of the N-terminal domain led to specific function of the individual CDPKs $[16,17]$. The protein kinase domain contains a catalytic Ser/Thr protein kinase domain with a ATP binding site and is adjacent to the auto-inhibitory domain, acting as a pseudosubstrate combined with kinase domain to maintain CDPK inactive $[18,19]$. The $\mathrm{C}$-terminal regulatory calmodulin-like domain contained one to four EFhand motifs for $\mathrm{Ca}^{2+}$ binding, which was the center of $\mathrm{Ca}^{2+}$ sensor. The $\mathrm{Ca}^{2+}$ binding led to a change in the protein structure, altered the auto-inhibitory domain, and then activated the CDPKs [20].

A number of studies from various plant species confirmed that CDPK genes played important roles in regulating plant growth and response to various stimuli, including light, hormones, wounding, abiotic and biotic stresses $[9,21-23]$. As for the critical roles that CDPKs played in $\mathrm{Ca}^{2+}$ signaling transduction, many studies presented their functions in plant growth and development, including pollen tube growth, nutrient transport, seed development and germination, stem and petiole elongation. For example, the anatomical analysis of Atcpk 28 mutant has been revealed that AtCPK28 acted as a developmentally controlled regulator for coordinated stem and petiole elongation, and vascular development [24]. Besides, AtCPK17 and AtCPK34 were found earlier to be essential to pollen fitness, and transduce $\mathrm{Ca}^{2+}$ signals to increase the rate of pollen tube tip growth and facilitate a response to tropism cues [25]. In rice, OsCDPK2 and OsCDPK11 have been reported to be essential for seed development, while further study revealed that over-expression OsCDPK2 could disrupt seed development $[26,27]$. Multiple researches proved that CDPKs were involved in response to environmental stress stimuli in conjunction with $\mathrm{ABA}$ signaling transduction [12, 16, 28]. In Arabidopsis, CPK10, possibly by interacting with $\mathrm{HSP} 1$, was involved in $\mathrm{Ca}^{2+}$-mediated regulation of stomatal movements under drought treatment and played important roles in ABA signaling [29]. Lossof-function mutations of CPK4 and CPK11 exhibited pleiotropic ABA-insensitive phenotypes and decreased tolerance of seedlings to salt stress, further study showed that CPK4 and CPK11 positively regulated calciummediated ABA signaling pathways through the phosphorylation of two ABA-responsive transcription factors, ABF1 and ABF4 [28]. Over-expression of OsCDPK7 enhanced plant tolerance to salinity/drought by inducting some stress-responsive genes, but not to cold, while OsCDPK13 and OsCPK17 were supposed to be important signaling components for response to cold stress in rice [30-32]. Recent studies have provided compelling evidence for the involvement of CDPKs in immunity signaling and plant disease resistance. CDPKs could act synergistically or independently with the MAPK cascade in regulating PAMP-triggered immunity signaling, or phosphorylate distinct substrates in regulating effectortriggered immunity signaling, via phosphorylating WRKY transcription factors for immune gene expression and Rbohs for ROS production. For example, AtCDPK4/ 5/6/11 could regulate MAMP- or PAMP-triggered immunity and phosphorylate WRKY transcription factors to regulate gene expression [33]. Moreover, although most of CDPKs exhibited positive roles in regulating plant growth and response to environmental stimuli, some CDPKs played negative roles. For instance, atcpk21 and atcpk 23 mutants showed increased tolerance to drought and salt stresses, suggesting that AtCPK21 and AtCPK23 acted as negative regulators in Arabidopsis responses to abiotic resistance [34, 35] Interesting, AtCPK12 might be a balancer in ABA signaling pathway, since AtCPK12 could phosphorylate ABF1 and ABF4 as well as ABI2 [36, 37].

As a critical role of the $\mathrm{Ca}^{2+}$-signaling pathway, CDPKs were encoded by a large gene family in various plant species. To date, genome-wide analyses have identified 34 CDPK genes in Arabidopsis [9, 18], 31 CDPK genes in rice [38], 20 CDPK genes in wheat [39], 35 $C D P K$ genes in maize [40], and $41 C D P K$ genes in cotton [41]. Brachypodium distachyon, which has been whole genome sequenced, became a attractive model organism for crops and herbaceous functional genomics research [42-44]. Considering the importance of CDPK genes as promising candidates for regulation of plant stress tolerance and few studies on $B$. distachyon were available, it was of interest for us to isolate CDPKs from $B$. distachyon. In this study, a total 30 CDPK family genes were identified from $\mathrm{Bd} 21$ genome, and the gene characterizations and phylogenies have been 
systematically analyzed. Furthermore, an expression heatmap of $B d C D P K s$ in response to different hormones and abiotic stresses was also exhibited, a predicted coexpression network was also discussed. The identification and systematical study for $C D P K$ genes from $B$. distachyon will provide fundamental information for exploring the functions of CDPKs in integrating $\mathrm{Ca}^{2+}$ signalling pathways in $B$. distachyon's adaptation to vagaries of environments.

\section{Results and discussion}

Identification of $30 B d C D P K$ genes from the $B$. distachyon plants

A total of $30 C D P K$ family genes were identified in $B$. distachyon, using known rice and Arabidopsis CDPK proteins as query sequences (Table 1 and Additional file 6) $[9,38]$. We named these genes $B d C D P K 1$ to $B d C D P K 30$ according to the position of the genes on chromosomes. The detailed gene information for these $B d C D P K$ genes, such as gene names, Locus IDs, gene locations, peptide lengths, conserved domain and site locations, and parameters for the deduced polypeptides, are listed in Table 1. The BdCDPKs identified in our study varied markedly from 508 amino acids (BdCDPK18) to 623 amino acids (BdCDPK03), ranged in molecular mass from $56.8 \mathrm{kDa}$ to $68.7 \mathrm{kDa}$, and the predicted isoelectric points varied from 4.94 (BdCDPK28) to 9.35 (BdCDPK04), which were comparable with CDPKs from other plant species $[9,38,45]$. The result of subcellular localization prediction showed that most of BdCDPKs were located in cytoplasmic, other of them were predicted to exit in chloroplast or mitochondrial, which was consistent with the fact that CDPKs acted as $\mathrm{Ca}^{2+}$ sensors to integrate extracellular stimuli [46]. The 30 identified $B d C D P K$ genes were distributed on all five chromosomes (Fig. 1). The number of $B d C D P K$ genes mapped on each chromosome was uneven and ranged from 2 to 9. Ten $B d C D P K$ genes were present on chromosome 1, representing $33.3 \%$ of the total $C D P K$ genes, followed by seven each on chromosomes 2 and 4, five on chromosomes 3 , and two on chromosomes 5 (Table 1 and Fig. 1).

To dissect the evolutionary relationships of BdCDPK family members, all BdCDPK full-length amino acid sequences were used to construct an unrooted tree (Additional file 7). Based upon sequence homology, BdCDPK family members were clustered into four subgroup (IIV), which was consistent with the previous works in Arabidopsis, rice, maize, and so on [9, 38, 40, 47]. Subgroup IV contained the least members, with three members, in which, the BdCDPK12 showed distant relationship with other members in this subgroup. Subgroup I was the most complex, with 11 members, while Subgroups II and III contained eight members each.
Subgroups I-III showed more closer in sequence identity to each other than to subgroup IV, but it remained unknown whether such a pattern of clustering reflected any functional differences among these subgroups.

\section{Structural divergence and tissue-specific expression of BdCDPKs}

The gene structure provides information of possible structural evolutionary relationships among gene families. To gain further insight into the structural diversity of $B d C D P K$ genes, we constructed a separate unrooted phylogenetic tree using the full-length BdCDPK protein sequences, and compared it with the exon/intron organization of the corresponding gene sequence (Fig. 2). As reflected by the evolutionary relationship of these CDPK proteins, most of the BdCDPK members clustered in the same subfamily shared very similar exonintron structures, including intron numbers and exon/ intron lengths, and although the lengths varied, the number and/or locations of intron insertions were seemed similar. Most $B d C D P K$ genes from subgroup I possessed seven exons, except for $B d C D P K 18 / 22$ and $B d C D P K 21$, which contained six and two exons, respectively. Most genes in subgroup II and III had 6-8 exons, subgroup IV possessed 12 exons except BdCDPK12, these traits are also found in Arabidopsis and rice [38, $45]$. Since genes in the joint phylogenetic tree were considered the related sister pairs and triplets [48, 49], fourteen related sister pairs among the $B d C D P K$ gene family, were displayed very similar intron/exon scatter in terms of intron/exon length and number. This conserved exon/intron structure in each group and sister gene pairs, supported the close evolutionary relationship of these CDPKs and the introduced classification of groups. Other $B d C D P K$ genes were showed divergent gene structure, suggesting that the function of these genes might be diversified.

Extensive studies have proved that the function of gene was often correlated with its transcriptional profile. Previous findings have suggested that the CDPK gene family was involved in plant growth and development $[23,50,51]$. Since no CDPKs in B. distachyon has been previously documented, and to investigate the divergence of homologs and putative functions of $C D P K$ genes in $B$. distachyon growth and development, we analyzed the expression patterns of $C D P K$ genes in different tissues. The results showed high alterations in expression levels among different CDPK group genes in $B$. distachyon, and a similar expression pattern in same CDPK group genes. Most paralogous genes which clustered as sister branches in the phylogenetic tree (Fig. 2a) and shared sequence identities no less than $90 \%$ presented largely similar expression patterns (Fig. 2c), implying their functional redundancy. Notably, BdCDPKO9 and 
Table 1 CDPK genes in B. distachyon

\begin{tabular}{|c|c|c|c|c|c|c|c|c|c|c|c|c|}
\hline $\begin{array}{l}\text { Gene } \\
\text { Name }\end{array}$ & Gene Locus & $\begin{array}{l}\text { Genebank } \\
\text { Acc. No. }\end{array}$ & $\begin{array}{l}\text { ORF } \\
\text { (bp) }\end{array}$ & $\begin{array}{l}\text { Exon } \\
\text { No. }\end{array}$ & $\begin{array}{l}\text { Pepide } \\
\text { length }\end{array}$ & PKD & $\begin{array}{l}\text { EF-hand } \\
\text { domain }\end{array}$ & $\mathrm{Pl}$ & $\begin{array}{l}\mathrm{MW} \\
(\mathrm{KD})\end{array}$ & $\begin{array}{l}\text { N- } \\
\text { myrist }\end{array}$ & $\begin{array}{l}\mathrm{N}- \\
\text { Palmit }\end{array}$ & Subcellular Localization $^{c}$ \\
\hline$\overline{\mathrm{BdCDPKO1}}$ & Bradi1g04440 & $\begin{array}{l}\mathrm{XM} \\
010 \overline{2} 29652\end{array}$ & 1602 & 8 & 533 & $\begin{array}{l}58- \\
316\end{array}$ & $366-533$ & 6.31 & 59.96 & $\mathrm{~N}$ & $\mathrm{Y}$ & pero: 6, mito: 5, chlo: 2 \\
\hline BdCDPK02 & Bradi1g06270 & $\begin{array}{l}X M \\
010 \overline{2} 30428\end{array}$ & 1773 & 7 & 590 & $\begin{array}{l}127- \\
385\end{array}$ & $435-590$ & 5.29 & 64.59 & N & Y & vacu: 6, chlo: 4, nucl: 2, pero: 1 \\
\hline BdCDPK03 & Bradi1g06300 & $\begin{array}{l}\mathrm{XM} \\
024 \overline{4} 56669\end{array}$ & 1872 & 7 & 623 & $\begin{array}{l}157- \\
415\end{array}$ & $465-623$ & 5.84 & 68.48 & N & Y & chlo: 6, vacu: 6, nucl: 1 \\
\hline BdCDPKO4 & Bradi1g12150 & $\begin{array}{l}\text { XM } \\
003 \overline{5} 59516\end{array}$ & 1863 & 6 & 620 & $\begin{array}{l}109- \\
405\end{array}$ & $455-620$ & 9.35 & 68.74 & N & Y & $\begin{array}{l}\text { chlo: } 6 \text {, vacu: 3, E.R.: 2, nucl: 1.5, } \\
\text { cysk_nucl: } 1.5\end{array}$ \\
\hline BdCDPK05 & Bradi1g24240 & $\begin{array}{l}X M \\
003562825\end{array}$ & 1617 & 8 & 538 & $\begin{array}{l}64- \\
322\end{array}$ & $372-538$ & 6.98 & 60.5 & N & Y & cyto: 7, pero: 3, E.R.: 2, plas: 1 \\
\hline BdCDPK06 & Bradi1g26310 & $\begin{array}{l}X M \\
024 \overline{4} 56613\end{array}$ & 1599 & 8 & 532 & $\begin{array}{l}84- \\
342\end{array}$ & $391-532$ & 5.8 & 59.38 & N & Y & chlo: 8 , cyto: 3 , nucl: 2 \\
\hline BdCDPK07 & Bradi1g52567 & $\begin{array}{l}\mathrm{XM} \\
003 \overline{5} 57252\end{array}$ & 1551 & 12 & 516 & $\begin{array}{l}53- \\
313\end{array}$ & $363-516$ & 7.63 & 57.85 & N & Y & $\begin{array}{l}\text { cysk: } 7 \text {, cyto: } 3 \text {, chlo: } 1 \text {, nucl: } 1 \text {, } \\
\text { plas: } 1\end{array}$ \\
\hline BdCDPK08 & Bradi1g56970 & $\begin{array}{l}X M \\
010 \overline{2} 30066\end{array}$ & 1704 & 7 & 567 & $\begin{array}{l}105- \\
363\end{array}$ & $413-567$ & 5.17 & 62.42 & N & Y & $\begin{array}{l}\text { E.R.: } 5 \text {, chlo: } 2 \text {, nucl: } 2 \text {, cyto: } 1 \text {, } \\
\text { plas: } 1 \text {, vacu: } 1 \text {, pero: } 1\end{array}$ \\
\hline BdCDPK09 & Bradi1g76560 & $\begin{array}{l}\text { XM } \\
024 \overline{4} 56675\end{array}$ & 1653 & 7 & 550 & $\begin{array}{l}80- \\
339\end{array}$ & $389-550$ & 5.45 & 61.51 & N & Y & $\begin{array}{l}\text { nucl: } 3.5 \text {, cyto nucl: } 3.5 \text {, mito: } 3 \text {, } \\
\text { plas: } 3, \text { cyto: } 2.5 \text {, chlo: } 2\end{array}$ \\
\hline BdCDPK10 & Bradi2g15520 & $\begin{array}{l}\mathrm{XM} \\
003 \overline{5} 67783\end{array}$ & 1647 & 8 & 548 & $\begin{array}{l}96- \\
354\end{array}$ & $404-548$ & 6.56 & 62.12 & Y & N & chlo: 5 , nucl: 5 , pero: 3 \\
\hline BdCDPK11 & Bradi2g21390 & $\begin{array}{l}X M \\
003568155\end{array}$ & 1551 & 7 & 516 & $\begin{array}{l}62- \\
320\end{array}$ & $370-516$ & 5.59 & 56.94 & N & Y & $\begin{array}{l}\text { chlo: 3, plas: 3, vacu: 2, E.R.: 2, } \\
\text { nucl: } 1.5 \text {, cysk_nucl: } 1.5\end{array}$ \\
\hline BdCDPK12 & Bradi2g21790 & $\begin{array}{l}\text { XM } \\
003566058\end{array}$ & 1575 & 7 & 524 & $\begin{array}{l}13- \\
298\end{array}$ & $364-524$ & 5.33 & 58 & N & N & $\begin{array}{l}\text { chlo: } 6 \text {, cyto: } 4 \text {, nucl: } 3.5 \text {, nucl__ } \\
\text { plas: } 2.5\end{array}$ \\
\hline BdCDPK13 & Bradi2g22750 & $\begin{array}{l}X M \\
003568218\end{array}$ & 1647 & 7 & 548 & $\begin{array}{l}74- \\
332\end{array}$ & $382-548$ & 6.25 & 60.79 & N & Y & $\begin{array}{l}\text { cyto: } 4 \text {, mito: } 3 \text {, chlo: 2, E.R.: 2, } \\
\text { pero: } 1 \text {, cysk: } 1\end{array}$ \\
\hline BdCDPK14 & Bradi2g43910 & $\begin{array}{l}\text { XM } \\
003569338\end{array}$ & 1581 & 8 & 526 & $\begin{array}{l}74- \\
332\end{array}$ & $382-526$ & 5.8 & 59.44 & Y & N & mito: 8, chlo: 4, nucl: 1 \\
\hline BdCDPK15 & Bradi2g52870 & $\begin{array}{l}X M \\
003 \overline{5} 64390\end{array}$ & 1545 & 6 & 514 & $\begin{array}{l}59- \\
317\end{array}$ & $367-514$ & 5.45 & 56.78 & N & Y & $\begin{array}{l}\text { chlo: 4, plas: 3, nucl: } 2.5, \text { cyto: } 2 \text {, } \\
\text { cysk_nucl: } 2 \text {, vacu: } 1\end{array}$ \\
\hline BdCDPK16 & Bradi2g54080 & $\begin{array}{l}\mathrm{XM} \\
024 \overline{4} 58897\end{array}$ & 1686 & 6 & 561 & $\begin{array}{l}62- \\
320\end{array}$ & $370-561$ & 6.49 & 63.26 & N & Y & $\begin{array}{l}\text { chlo: } 4 \text {, cyto: } 4 \text {, mito: } 2 \text {, E.R.: } 1 \text {, } \\
\text { pero: } 1 \text {, cysk: } 1\end{array}$ \\
\hline BdCDPK17 & Bradi3g02600 & $\begin{array}{l}X M \\
010 \overline{2} 35446\end{array}$ & 1563 & 12 & 520 & $\begin{array}{l}57- \\
317\end{array}$ & $367-520$ & 8.99 & 58.64 & Y & Y & cyto: 7 , chlo: 2, nucl: 2, mito: 2 \\
\hline BdCDPK18 & Bradi3g32187 & $\begin{array}{l}\text { XM } \\
003 \overline{5} 71966\end{array}$ & 1527 & 6 & 508 & $\begin{array}{l}66- \\
324\end{array}$ & $374-508$ & 5.23 & 57.16 & N & Y & $\begin{array}{l}\text { mito: 4, nucl: 3, chlo: 2, cyto: 2, } \\
\text { plas: } 1 \text {, pero: } 1\end{array}$ \\
\hline BdCDPK19 & Bradi3g41770 & $\begin{array}{l}X M_{\overline{5}} \\
00372421\end{array}$ & 1740 & 3 & 579 & $\begin{array}{l}78- \\
368\end{array}$ & $418-579$ & 6.5 & 63.84 & Y & Y & $\begin{array}{l}\text { chlo: 5, cyto: 2, mito: 2, nucl: } 1 \text {, } \\
\text { vacu: 1, E.R.: 1, cysk: } 1\end{array}$ \\
\hline BdCDPK20 & Bradi3g51970 & $\begin{array}{l}\text { XM } \\
003570070\end{array}$ & 1671 & 7 & 556 & $\begin{array}{l}98- \\
356\end{array}$ & $406-556$ & 5.45 & 56.78 & Y & Y & $\begin{array}{l}\text { mito: } 10.5 \text {, chlo_mito: } 7.5 \text {, chlo: } \\
3.5\end{array}$ \\
\hline BdCDPK21 & Bradi3g60750 & $\begin{array}{l}X M \\
003 \overline{5} 70682\end{array}$ & 1599 & 2 & 532 & $\begin{array}{l}57- \\
325\end{array}$ & $375-532$ & 5.13 & 58.5 & Y & Y & cyto: 7, mito: 4, nucl: 2 \\
\hline BdCDPK22 & Bradi4g07280 & $\begin{array}{l}X M \\
010 \overline{2} 40643\end{array}$ & 1833 & 6 & 610 & $\begin{array}{l}158- \\
416\end{array}$ & $466-610$ & 5.92 & 67.78 & Y & Y & $\begin{array}{l}\text { chlo: } 5 \text {, mito: } 3.5 \text {, cyto_mito: } 2.5 \text {, } \\
\text { cyto: 2, nucl: 1, E.R.: } 1\end{array}$ \\
\hline BdCDPK23 & Bradi4g24390 & $\begin{array}{l}X M \\
003 \overline{5} 77735\end{array}$ & 1557 & 7 & 518 & $\begin{array}{l}52- \\
310\end{array}$ & $360-518$ & 5.28 & 57.05 & N & N & chlo: 11, E.R.: 2 \\
\hline BdCDPK24 & Bradi4g26317 & $\begin{array}{l}\text { XM } \\
003 \overline{5} 76298\end{array}$ & 1599 & 5 & 532 & $\begin{array}{l}75- \\
333\end{array}$ & $383-532$ & 5.6 & 58.44 & Y & Y & cyto: 7, chlo: 4, nucl: 2 \\
\hline BdCDPK25 & Bradi4g35100 & $\begin{array}{l}\mathrm{XM} \\
003 \overline{5} 78386\end{array}$ & 1698 & 8 & 565 & $\begin{array}{l}88- \\
358\end{array}$ & $426-565$ & 5.95 & 62.54 & Y & Y & $\begin{array}{l}\text { chlo: } 3 \text {, mito: } 3 \text {, cyto: } 2 \text {, plas: } 2 \text {, } \\
\text { vacu: } 2, \text { nucl: } 1\end{array}$ \\
\hline BdCDPK26 & Bradi4g39870 & $\begin{array}{l}\text { XM } \\
003 \overline{5} 78709\end{array}$ & 1713 & 6 & 570 & $\begin{array}{l}81- \\
339\end{array}$ & $389-570$ & 6.14 & 63.3 & N & Y & chlo: 6, mito: 6, cyto: 1 \\
\hline BdCDPK27 & Bradi4g40300 & $\begin{array}{l}\text { XM } \\
003 \overline{5} 78741\end{array}$ & 1572 & 7 & 523 & $\begin{array}{l}48- \\
306\end{array}$ & $356-523$ & 5.53 & 57.65 & N & $\mathrm{N}$ & chlo: 7, E.R.: 3, plas: 2, nucl: 1 \\
\hline BdCDPK28 & Bradi4g43400 & $\begin{array}{l}X M \\
003578916\end{array}$ & 1650 & 6 & 549 & $\begin{array}{l}91- \\
349\end{array}$ & $399-549$ & 4.94 & 60.07 & N & Y & cyto: 10 , nucl: 3 \\
\hline BdCDPK29 & Bradi5g18250 & $\begin{array}{l}\text { XM } \\
010 \overline{2} 41951\end{array}$ & 1719 & 7 & 572 & $\begin{array}{l}99- \\
388\end{array}$ & $437-572$ & 6.6 & 64.05 & Y & Y & cyto: 7 , chlo: 4 , nucl: 2 \\
\hline BdCDPK30 & Bradi5g19430 & $\begin{array}{l}\text { XM } \\
003 \overline{5} 80349\end{array}$ & 1686 & 7 & 561 & $\begin{array}{l}98- \\
356\end{array}$ & $406-561$ & 5.49 & 61.59 & Y & Y & mito: 9.5, chlo_mito: 7, chlo: 3.5 \\
\hline
\end{tabular}

ORF Open Reading Frame, PKD Protein kinase domain, $P I$ isoelectric point

a. The myristoylation site was predicted by Myristoylator program in ExPASy (http://web.expasy.org/myristoylator/)

b. The palmitoylation site was predicted by CSS-plam4.0 (http://csspalm.biocuckoo.org/)

c. chlo Chloroplast, cysk Cytoskeleton, cyto Cytoplasmic, E.R. Endoplasmic reticulum, mito Mitochondrial, nucl Nuclear, pero Peroxysome, plas

Plasma membrane, vacu Vacuole 


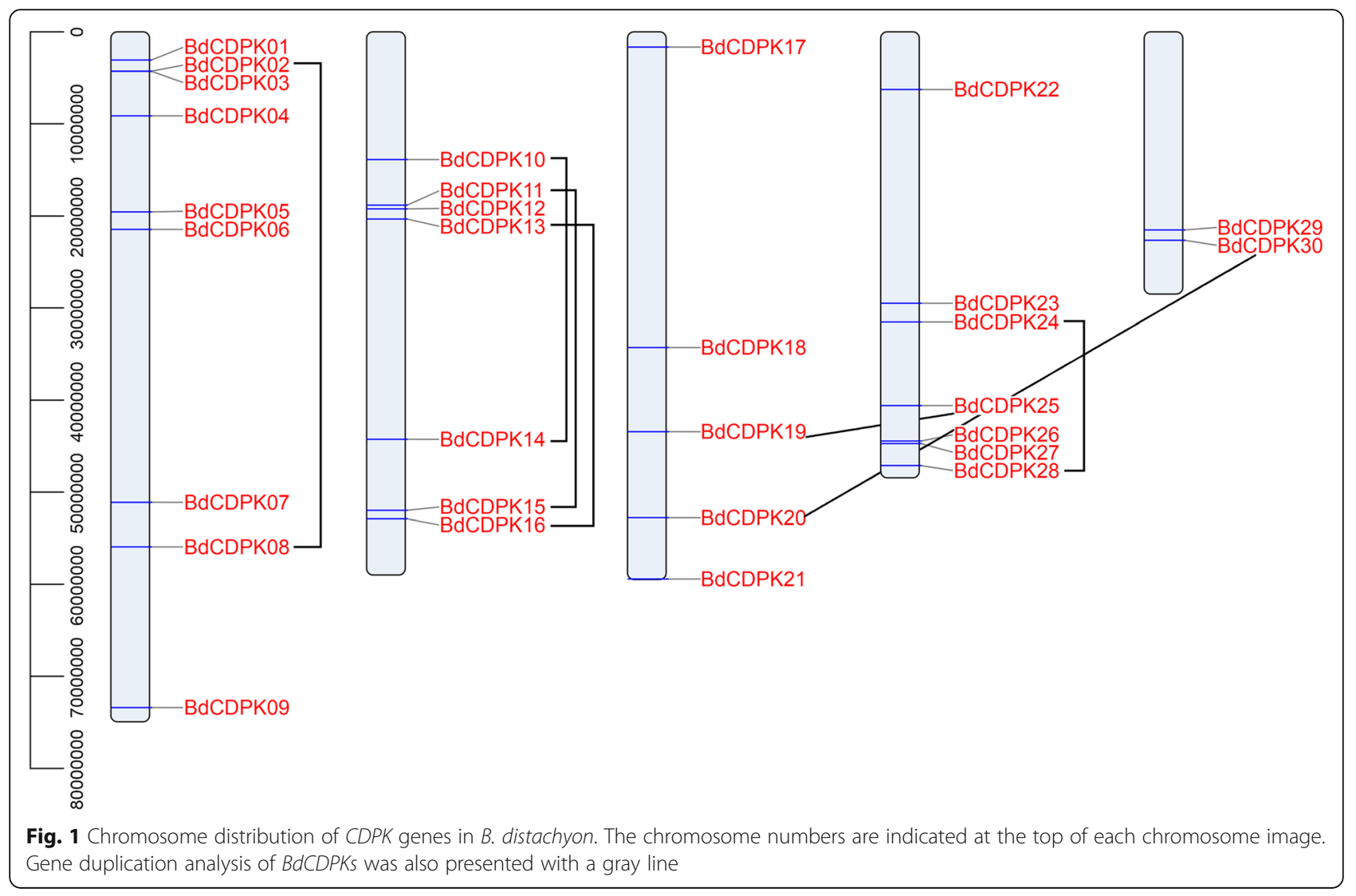

$B d C D P K 18, B d C D P K 03$ and BdCDPK22, BdCDPK10 and $B d C D P K 14$, and $B d C D P K 13$ and $B d C D P K 16$ were almost exclusively expressed in seed, while $B d C D P K 07$ and $B d C D P K 17$ were lowest in seed, but highly expressed in root and stem, suggesting that they might be involved in these organs' development and growth. However, some paralogous exhibited rather different expression patterns. For instance, BdCDPKO8 and $B d C D P K 19$ showed high expression level in root and seed, whereas their paralogs (BdCDPKO2 and $B d C D P K 25$, respectively) appeared to have relatively high expression in stem and flower. These data indicate that the CDPK gene family members might be involved in the growth and development of different tissues or organs.

To investigate the protein structural and functional diversity of BdCDPKs, motif and domain analyses were performed based on the phylogenetic relationship (Table 1 and Fig. 3). Generally, 15 conserved motifs within the $B$. distachyon CDPKs were identified using online MEME tools, which can help us investigate their function [52]. As mentioned above, the unrooted phylogenetic tree showed that BdCDPKs were broadly divided into four major subgroups. Eight of the motifs (motif 7, $9,5,10,2,1,6$, and 4) were shared by all of the CDPK proteins. Meanwhile, the conserved gene structures revealed similar motifs among groups. For example, motif 14 was only presence in subgroup III, while most of this subgroup members did not contain motif 13 . The motif analysis results illustrated that conserved motif structures within each group supported their close evolutionary relationship, while there might be functional divergences between different groups. Further, the protein structure of BdCDPKs were predicting using InterPro and SMART protein databases and sequence alignment (Fig. 3 and Additional files 8, 9 and 10). Results showed that all CDPKs identified in our study were possessed of four characterized domains, including a variable N-terminal domain, a catalytic Ser/Thr protein kinase domain, an autoinhibitory domain, and a EF-hand domain, which were considered as the typical CDPK structure [19].

The variable N-terminal domain of several CDPK proteins had myristoylation motif with an N-terminal glycine residue, which was thought to be critical for mediating protein-protein and protein-lipid interactions. Myristoylation played an essential role in membrane targeting and functioned widely in a variety of signal transduction pathways $[53,54]$. As a kind of important $\mathrm{Ca}^{2+}$ sensor, CDPKs had an N-myristoylation motif tended to localize in the plasma membranes, suggesting that myristoylation was required for membrane binding and $\mathrm{Ca}^{2+}$ 


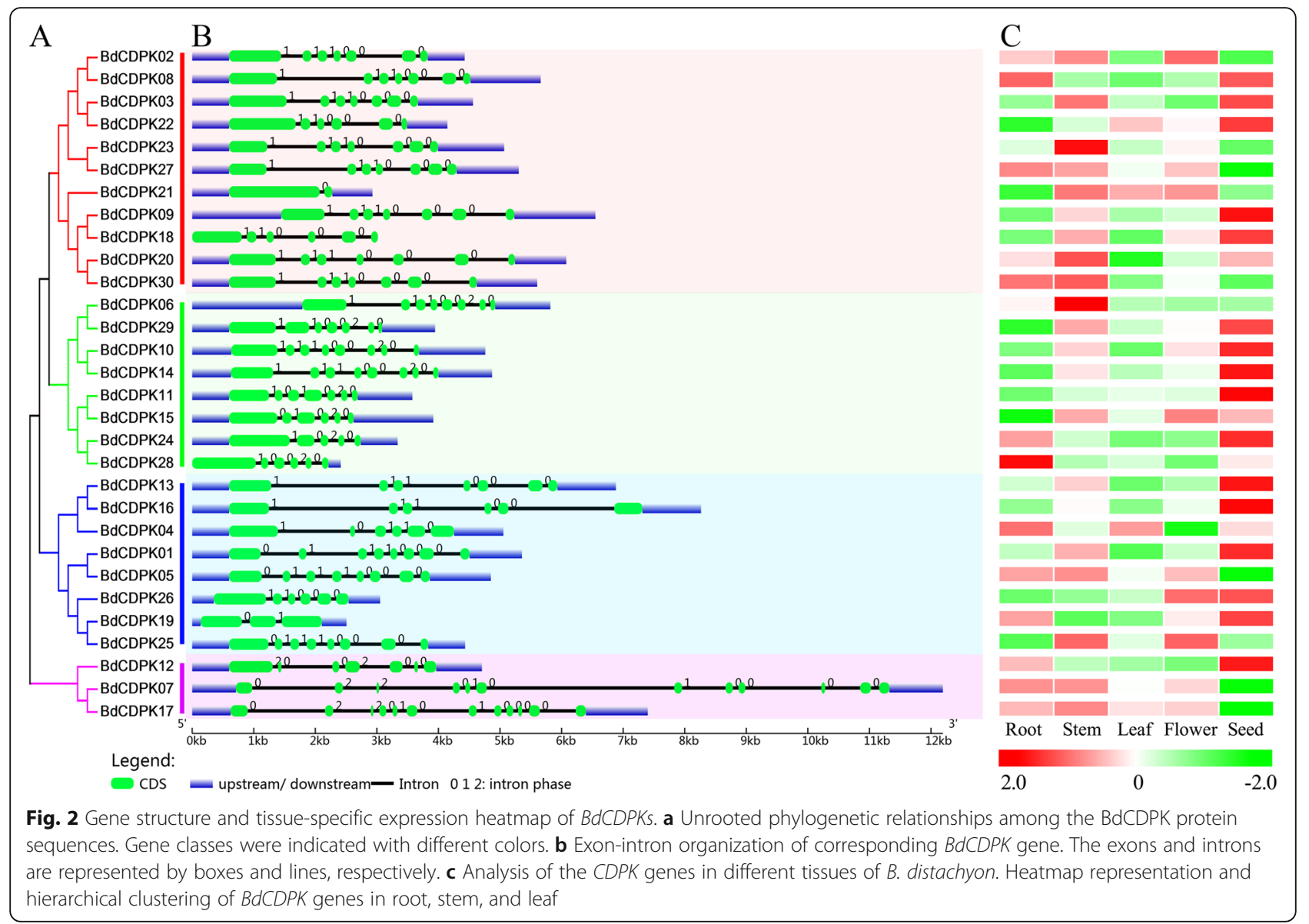

signal transduction pathways [29, 39, 55-57]. In addition, another type of lipid modification, palmitoylation, could enhance the hydrophobicity of proteins and contributes to their membrane association, playing a significant role in subcellular trafficking of proteins between membrane compartment [55, 58]. Among 30 BdCDPKs, 11 CDPKs were predicted to have myristoylation motifs, and 5 members lacked palmitoylation site at the $\mathrm{N}$-terminus (Table 1). Exceptionally, the membrane association of CDPKs might be affected by other motifs. For instance, ТaCPK3 and 15, lacking myristoylation motifs, were also shown to be membrane-bounded, lacked myristoylation motifs [39], while a ZmCK1::hGFP fusion protein was found to localize to the cytoplasm and nucleus, which was predicted to have an $\mathrm{N}$ myristoylation [59]. Therefore, other motifs may affect the subcellular localizations, and it was still needed to be further characterized experimentally.

All members of BdCDPK contained a protein kinase domain (Interpro acc. no. IPR000719, SMART acc. no. SM000220), which was composed of motifs 7, 9, 5, 10, 2, 1 , and 6 as shown in Fig. 3. In the protein kinase domain, it contained motif 7 and 2 as ATP binding site (IPR017441) and serine/threonine-protein kinase active site (IPR008271), respectively. The protein kinases domain could catalyze the gamma phosphate transferring to amino acid residues (such as serine and threonine) in a protein substrate side chain from nucleotide triphosphates (often ATP), resulting in a conformational change affecting protein function [60]. All members of BdCDPKs contained an ATP-binding site, suggesting that these BdCDPKs could used ATP as source of phosphate groups to phosphorylate target substrates in signal transduction pathways. Although the protein kinases domain is extremely conservation, we notice that the sequences of serine/threonine-protein kinase active site among different subgroups contain a large number of variations. For example, the sequences of protein kinase active site in subgroup III was quite different with subgroups I and II (Additional file 9). Similarly, the residues in protein kinase active site of subgroup IV, especially BdCDPK12, were less conservative compared with subgroups I - III.

The calmodulin-like domain contained $\mathrm{Ca}^{2+}$ binding EF-hand structure that made CDPK proteins to function as a $\mathrm{Ca}^{2+}$ sensor. Each EF-hand structure consists of a helix-loop-helix structure, and at least one $\mathrm{Ca}^{2+}$-binding site composed of 12 amino acids confers the $\mathrm{Ca}^{2+}$ - 


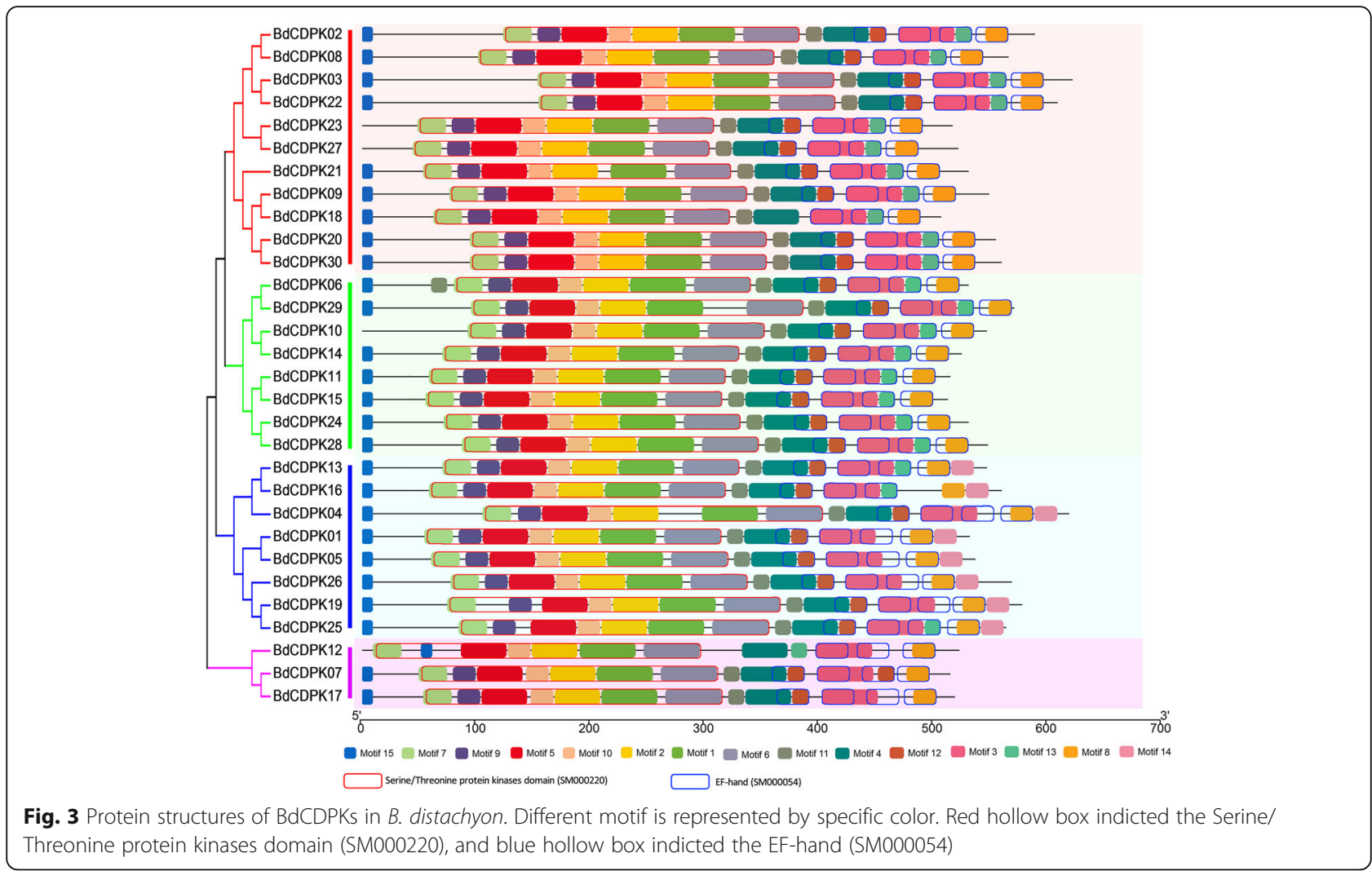

binding activity [61]. In $B$. distachyon, 26 CDPKs had four $\mathrm{Ca}^{2+}$ binding EF-hand structures (Interpro acc. no. IPR002048, SMART acc. no. SM000054), which might be composed of motif $4,12,3,13$, and 8 , four CDPKs (BdCDPK05, 12, 16, and 18) contained three EF-hand structures each (Fig. 3 and Additional files 8, 9 and 10). This difference in EF-hand structure was also found in the CDPK family of other plants [9, 38, 40, 62]. Further, the structure of EF-hands in $B$. distachyon were $\mathrm{D}_{1}-\mathrm{D}_{3}$ $S_{5}-E_{12}, D_{1}-D_{3}-S / N_{5}-E_{12}, D_{1}-D_{3}-S_{5}-E_{12}$, and $D_{1}-D_{3}-D_{5}-$ $\mathrm{E}_{12}$, respectively (Additional file 10). And results showed that EF2 and EF4 exhibited difference with CDPKs in Arabidopsis [63]. Studies have proved that the Cterminal EF-hand structures might be important for recognizing the autoinhibitory-junction domain when the $\mathrm{Ca}^{2+}$ regulated the activity of CDPKs $[60,64,65]$. Compared to $\mathrm{C}$-terminal EF-hand structures, $\mathrm{N}$-terminal EFhand structures (EF1 and EF2) with lower $\mathrm{Ca}^{2+}$-binding affinities played important roles in activating the kinases $[35,66]$. These results suggested a high conservation of this family through evolution.

\section{Phylogenetics and synteny analysis of BdCDPKs}

To explore the function and phylogenetic relationship of BdCDPK proteins between dicots and monocots, the dicot model plant Arabidopsis, the monocot model plant rice, and $B$. distachyon CDPK full-length amino acid sequences were used to construct an unrooted phylogenetic tree. The maximum likelihood phylogenetic distribution suggested that the organization of these BdCDPK proteins was very similar to each other in subgroup I, II, III, and IV, implying that CDPKs within these classes derived from a common ancestor (Additional file 11). In general, all CDPKs and their subgroups were present in monocots and dicots, indicating that the appearance of most of CDPKs in plants predated the monocot-dicot divergence and CDPK genes were conserved during evolution. Similar to the CDPKs in Arabidopsis and rice, subgroups I, II and III in B. distachyon consist of large numbers of CDPKs, which exhibit a great diversity in number among different plant species. For example, eleven CDPKs in subgroup I were found in $B$. distachyon, and eight CDPKs in subgroup II were found in $B$. distachyon. The members in subgroup IV contained the lowest number of CDPKs. However, nine AtCDPKs in the subgroups II was clustered into one sub-branch, which exhibited the difference between monocots and dicots, suggesting that these members might arise after dicot-monocot divergence. These results implied that the divergence in distribution of CDPK subgroups in different plant species might be because of the independent evolution of subgroup II among the different organisms. The phylogenetic similarity found in rice and $B$. distachyon, suggesting that they may have evolved 


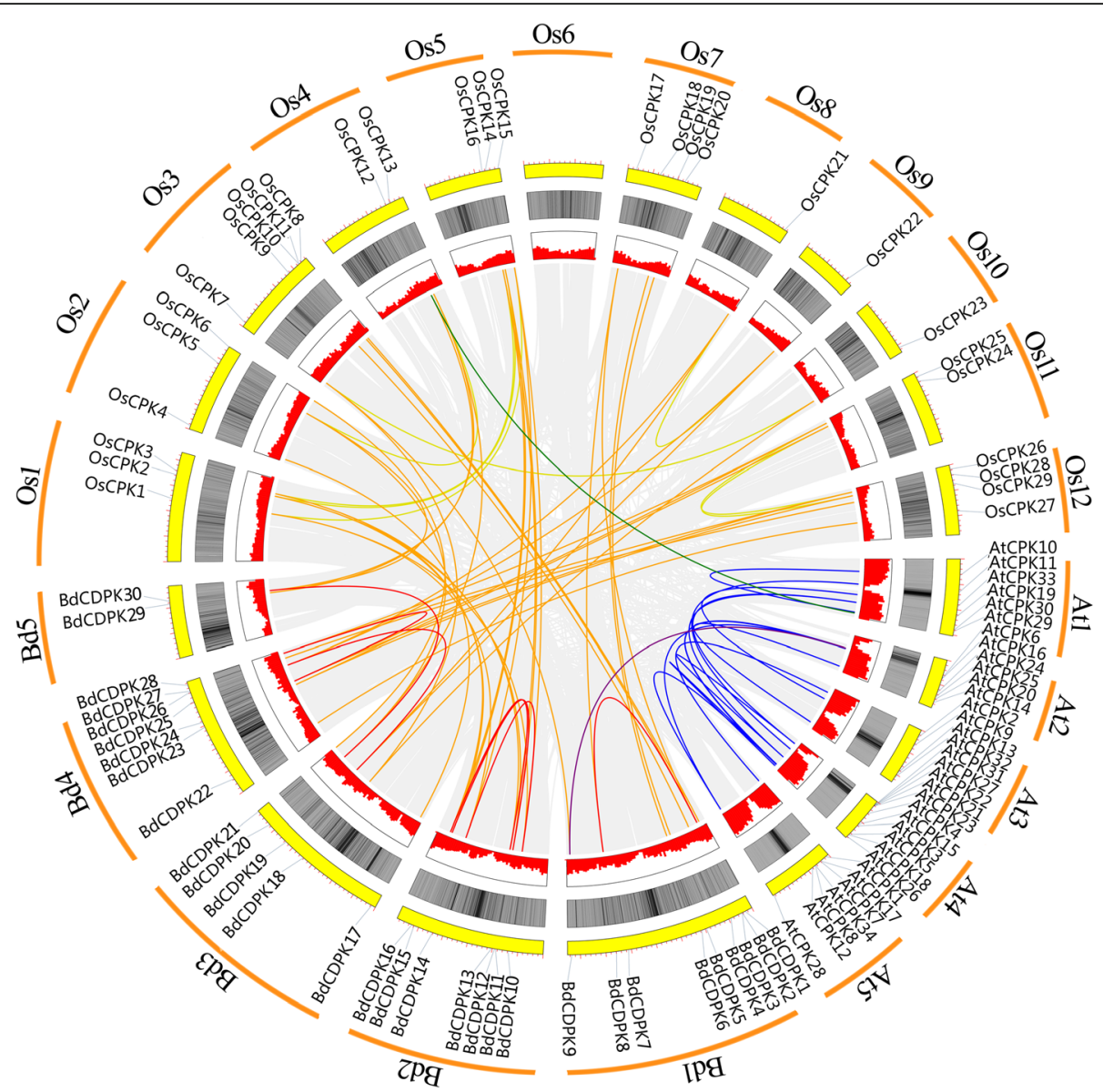

Fig. 4 Synteny analysis of CDPK genes among Arabidopsis, rice and B. distachyon. Gray lines in the background indicate the collinear blocks within Arabidopsis, rice and B. distachyon genomes, while the colored lines highlight the syntenic CDPK gene pairs. Schematic representation was displayed by using the CIRCOS software. The size of chromosomes was consistent with the actual pseudo-chromosome size. Positions are in Mb

conservatively, which was consistent with the synteny analysis results (Fig. 4). As a result, 72 collinear gene pairs among rice, Arabidopsis and B. distachyon CDPKs. Results indicated that large number of syntenic relationship events existed between rice and $B$. distachyon, indicating that many consensuses in CDPK protein may have existed before the species divergence between rice and $B$. distachyon. However, there are only one collinear gene pairs (AtCPK6 and BdCDPK09) existing between $B$. distachyon and Arabidopsis, suggesting that the origin of this gene pairs were very old.

\section{Expression profile of $B d C D P K$ genes}

Extensive research has revealed the crosstalk between CDPK and phytohormones in plant defense and development processes [36, 37, 67]. Phytohormones played well-established roles in regulating plant signaling networks [68]. Incipiently, CDPKs were known to modulate $\mathrm{Ca}^{2+}$-dependent plant responses caused by phytohormones, mostly cytokinins, auxins and gibberellins. For example, the activity of CDPK was higher in GA-treated seeds than in untreated ones [69], the transcript level of OsCDPK13 was increased by GA treatment in rice seedlings [70], and in Arabidopsis, CРК28 was identified as a key regulator of GA and JA levels [24, 71]. In tobacco leaves, a slight induction of NtCDPK1 expression was observed by treated with IAA [72], and the expression level of MsCPKs was increased after auxin (2, 4-D) treated in alfalfa [73]. Further, an increasing body of evidence has shown that CDPKs regulate ABA-mediated signal transduction in plants [28, 29, 74]. In Arabidopsis, CPK4 and CPK11 were found to positively regulate calcium-mediated ABA signaling, while CPK21 and CPK23 were identified to act as negative regulators in ABA signaling pathway [28, 35, 75]. To better understand the role of BdCDPKs in phytohormone signaling pathway, the expression levels of the $B d C D P K$ family genes in $B$. distachyon seedlings were detected by qRTPCR under various phytohormones treatments, including 6-BA, ABA, GA and NAA, and then the green-red gradient heatmaps were generated by PermutMatrix program. Firstly, the expression levels of eight genes were 
determined as marker genes to evaluate the phytohormones treatments (Additional files 12 and 13). The expression levels of all marker genes exhibited obviously increased after phytohormones treatments, which was consistent with previous studies [76-78]. In this study, most members of $B d C D P K$ genes exhibited a transcriptional expression changes in response to all tested phytohormones, and the transcriptional regulation of these $B d C D P K$ genes was shown great divergence (Fig. 5). The real-time qPCR results revealed that most of $B d C D P K$ genes (except BdCDPK05, BdCDPK15 and BdCDPK18) were induced at least one phytohormone treatment, and nine BdCDPKs (BdCDPK02, BdCDPK08, BdCDPK13, BdCDPK14, BdCDPK16, BdCDPK21, BdCDPK24, $B d C D P K 25$ and $B d C D P K 29)$ were induced by these four types of phytohormones. Among these genes, the expression of seven BdCDPKs (BdCDPK02, BdCDPK13, $B d C D P K 14, B d C D P K 16, B d C D P K 21, B d C D P K 25$ and $B d C D P K 29)$ were up-regulated within $12 \mathrm{~h}$ after phytohormone treatments, suggesting these $B d C D P K$ genes were related to early response in phytohormone treatments, while the expression level of $B d C D P K 24$ was increased at $24 \mathrm{~h}$ post-treatment, implying this $B d C D P K$ gene might be considered as a late response gene. As shown in Fig. 5, BdCDPKO8was significantly upregulated in the seedlings by treatment with all test phytohormones, suggesting BdCDPK08 might play critical roles in phytohormones-induced signaling pathway, and execute multifunction in plant growth and development, which was consistent with the previous reports that the homologs of $B d C D P K 08$ were played important roles in plant growth and development and response to abiotic and biotic stresses (Additional file 14) [32, 79-83]. It has been reported that CDPKs regulated ABA signal pathway by phosphorylating $A B A-r e s p o n s i v e ~ e l e m e n t ~ b i n d-$ ing factors (ABFs) and $A B A$ Insensitive (ABI). For example, AtCPK32 acted as an ABA signaling component that positively modulates the ABA-responsive gene expression via ABF4, while AtCPK12 was considered as a balancer in ABA signaling pathway by phosphorylating ABF1 and ABF4 as well as ABI2 [37, 74]. In response to exogenous $\mathrm{ABA}$, transcripts of an overwhelming majority of $B d C D P K$ genes were up-regulated within $3 \mathrm{~h}$, suggesting that $B d C D P K$ genes can quickly respond to $\mathrm{ABA}$ signal. It seems likely that expression level of $B d C D P K$ genes from subgroup I and II were significantly increased in response to ABA which is in agreement with the changes in AtCPK3/4/6/11/23 in subgroup I and II of Arabidopsis [63, 68]. In addition, BdCDPK23/27 kept at a high expression level after ABA treatment, and their homologous AtCPK4/11 was known to positively modulate calcium-mediated ABA signaling [28]. Although the role of CDPKs in Arabidopsis has been reported in many researches, the function of BdCDPKs in phytohormones signaling transduction remained to be studied in future.

It has been proven that many CDPKs play important roles in responses to cold, salt and drought, and the phytohormones were major modulators in plant adaptation
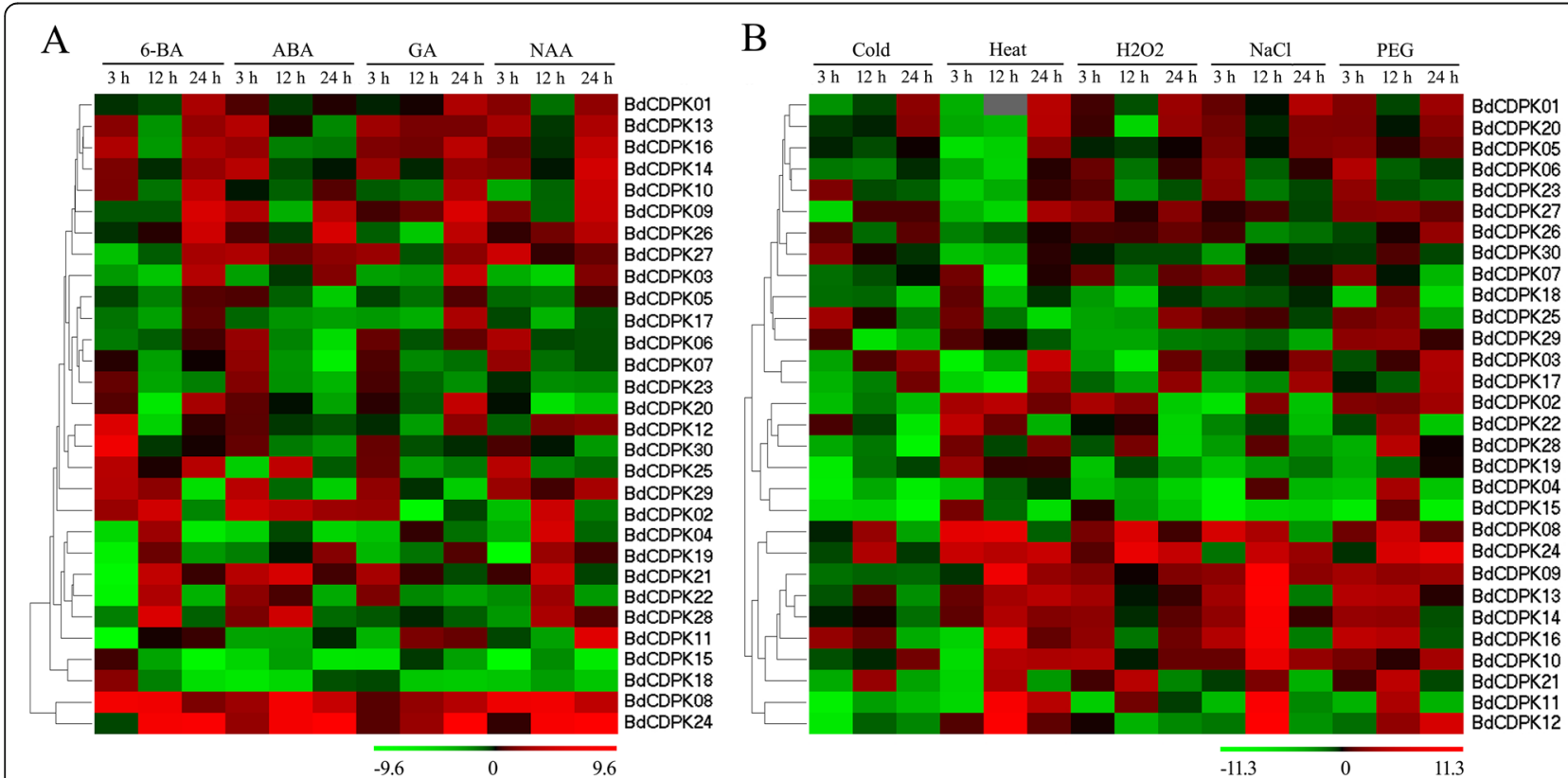

Fig. 5 Expression patterns of CDPK genes in B. distachyon in response to phytohormone (a) and abiotic stresses (b). 6-BA (6-benzylaminopurine, $20 \mu \mathrm{M}$ ); ABA (abscisic acid, $100 \mu \mathrm{M}) ; \mathrm{GA}$ (gibberellin A3, $10 \mu \mathrm{M}$ ); NAA (1-naphthylacetic acid, $5 \mu \mathrm{M})$ ); Cold for $4{ }^{\circ} \mathrm{C}$; Heat for $45^{\circ} \mathrm{C} ; \mathrm{H}_{2} \mathrm{O}_{2}(10 \mathrm{mM}$ ); $\mathrm{NaCl}(200 \mathrm{mM})$ and PEG (polyethylene glycol, 20\%), respectively. Levels of down expression (green) or up expression (red) are shown on a log2 scale from the high to the low expression of each BdCDPK gene 
and responses to various environmental stresses [2, 13, 84]. Transcriptome data showed that large numbers of $B d C D P K$ genes were up-regulated by kinds of abiotic stresses, including cold, heat, drought and submergence (Additional file 4). To further evaluate the possible functional divergence of $B d C D P K$ genes during abiotic stress and understand the relationship between phytohormone homeostasis and abiotic stresses, we determined the expression pattern of $B d C D P K$ genes in response to cold, heat, $\mathrm{H}_{2} \mathrm{O}_{2}, \mathrm{NaCl}$ and PEG treatments. Firstly, the expression levels of marker genes were increased after abiotic treatments, as reported in previous studies (Additional files 12 and 13) [77, 85-87]. Generally, the expression pattern of $B d C D P K$ genes in response to cold and heat stress was obviously different. For instance, 22 $B d C D P K$ genes were up-regulate after heat treatment, while most of these $B d C D P K$ genes were significantly down-regulate in response to cold stresses. Under cold stress, most of $B d C D P K$ genes were down-regulated at the early phase of cold treatment, while four members (BdCDPK16, 23, 25 and 30) were significantly induced, implying most of BdCDPKs might act as early negative regulator in response to cold stress. The expression level of $B d C D P K 01,03,10$ and 17 were up-regulated $24 \mathrm{~h}$ post-cold treatment, suggesting these $B d C D P K s$ were involved in the late response to cold stress. Under heat condition, most of $B d C D P K$ genes were up-regulated $12-24 \mathrm{~h}$ post treatment, while four $B d C D P K$ genes (BdCDPKO2, 13, 14 and 24) were persistently upregulated. It is possible that most of $B d C D P K$ genes were transcriptionally activated only at a certain time point, until the enzymes exert their functions [41, 88]. But there were still a few $B d C D P K$ genes which might execute their function continuously. Interestingly, it exhibited a similar expression pattern in the $B$. distachyon seedlings subjected to salt, drought and oxidative stresses, which was consisted with the previous reports that many CDPKs were involved in both salt and drought stresses, and they positively mediated tolerance to these stresses by protecting plants from reactive oxygen species (ROS) damage, with the uncontrolled generation of ROS being a common feature of these stresses [80, 89-91]. Notably, a set of genes (BdCDPK09, 10, 11, 12,13 , and 20 ) were up-regulated $0-12 \mathrm{~h}$ post treatment with $\mathrm{NaCl}$ and PEG, while they were up-regulated 12$24 \mathrm{~h}$ post treatment with heat stress, implying these BdCDPKs might play different roles in response to these stresses. The present study, together with the previously public transcriptome data, revealed that osmotic stress induced expression of a different pattern of genes compared with temperature stress, which was consist with the expression pattern of VaCPKs (Fig. 5 and Additional file 4) [88]. Interestingly, some gene pairs in the terminal nodes of the phylogenetic tree showed similar expression pattern under different treatments. For instance, $B d C D P K 02 / 08$ were up-regulated under heat, $\mathrm{H}_{2} \mathrm{O}_{2}$ and drought stresses, while $B d C D P K 10 / 14, B d C D P K 13 / 16$ and $B d C D P K 23 / 27$ were induced under $\mathrm{H}_{2} \mathrm{O}_{2}$, salt and drought stresses. These observations indicate that these CDPK genes might be function redundancy, or can cooperatively regulate a specific stimulation, which was consistent with the findings of many plants, such as CDPK gene in tomato, poplar and cucumber [62, 92, 93]. Nonetheless, some gene pairs exhibited a divergent transcriptional level. For example, BdCDPK08 was upregulated by salt stress, but the transcriptional level $B d C D P K 02$ was decreased under same condition. Transcriptional abundance of $B d C D P K 22$ was up-regulated by heat stress, while $B d C D P K 22$ was strongly downregulated after heat treatment. These results imply complex functionality of BdCDPKs in multiple signaling pathways, and the evolutional variation in cis- or transacting element of such genes. Synteny analysis results indicated 72 collinear blocks of CDPK genes among rice, Arabidopsis and B. distachyon CDPKs (Fig. 4). Intriguingly, large number of correlated functional connections in syntenic gene pairs have been found. For example, AtCPK4 was proved as a positive regulator in involved in tolerance to salt, drought and oxidative stresses, and its collinear gene $B d C D P K 23$ was also upregulated during salt, drought and oxidative stresses [28, 94]. Both BdCDPKO9 and its collinear gene OsCDPK7 were involved in the response to salt and drought stresses [30]. Thus, the synteny analysis among Arabidopsis, rice and $B$. distachyon could provide insights into the prediction of gene function for $C D P K$ genes. These results implied a conservation of gene function during the evolution of $C D P K$ genes.

\section{Prediction of co-regulatory and interaction networks of $B d C D P K s, B d W R K Y$ s and BdMAPK cascade genes}

$\mathrm{Ca}^{2+}$ was considered as a critical pathway trigger in response to environmental stimuli and developmental cues, and it was a ubiquitous secondary messenger in cellular signal transduction, which was decoded by various $\mathrm{Ca}^{2+}$ binding proteins and kinases such as CDPK [3]. Besides the $\mathrm{Ca}^{2+}$ signaling, MAPK cascade was a pivotal phosphorylation pathway to transmit external or internal signals to downstream effectors. WRKY transcription factors were one of the largest families of transcriptional regulators, which could form integral parts of signalling networks to modulate many plant processes. Here, to explore the potential regulatory networks between $B d C D P K s$ and $B d W R K Y s$ as well as that between $B d C D P K s$ and $B d M A P K$ cascade gene, we constructed the co-expression regulatory network among these genes upon different stress treatments by calculating the correlation coefficient of expression level 
between each two genes. Results showed that large number of $B d C D P K$ genes exhibited co-expression correlation with $B d W R K Y s$ and BdMAPK cascade gene, suggesting these genes might be involved in same regulatory pathway (Fig. 6 and Additional file 15). Reports proved that the CDPK and MAPK pathways were often triggered by same environmental stimuli and developmental cues, it has been speculated that a potential crosstalk might exist between these two important protein kinase families [67, 95]. For instance, CDPKs and MAPK cascades differentially regulated flg22-induced early genes through CDPK/MAPK parallel or CDPK/ MAPK synergistic regulation, implying an independent or co-regulation of transcription machinery in response to flg22 [12]. As shown in Fig. 6, BdCDPK25 showed positive co-expression levels with a large number of BdMAPKKKs, indicating that $B d C D P K 25$ might be a key regulators in MAPK pathways, which was consist with the result that OsCPK18 was identified as an upstream kinase of MAPK (MPK5) in rice [96]. However, the prediction protein-protein interaction (PPI) result showed that $B d C D P K 25$ didn't directly interact with MAPKKKs
(Additional file 16). Moreover, CDPK signaling has been reported to compromise stress-induced MAPK activation in tobacco [67]. In this study, we also found that $B d C D P K 07$ and $B d C D P K 12$ exhibited negative expression correlation with some MAPK cascade genes, implying these CDPKs might mediated the inhibition of MAPK activation. The prediction PPI result also showed that a set of BdCDPKs (BdCDPK06, 07, 09, 17, 18 and 23) were predicted to be interacted with BdMAPKs, implying that BdCDPKs might be involved in MAPK pathways through directly interacting with MAPKs, but not the upstream components of MAPK pathways, such as MAPKKs and MAPKKKs (Additional file 16). The regulatory network between $B d C D P K s$ and $B d W R K Y s$ was more complicated. As shown in Fig. 6, BdCDPK09/13/ $14 / 27$ showed a strong negative co-expression correlation with a set of $B d W R K Y s$, indicating that these BdCDPKs might be a repressors to negatively regulate the stress response in $B$. distachyon. BdWRKYs were also predicted to be interacted with several members of BdCDPKs, suggesting BdCDPKs might phosphorylate WRKY transcription factor to execute their function in

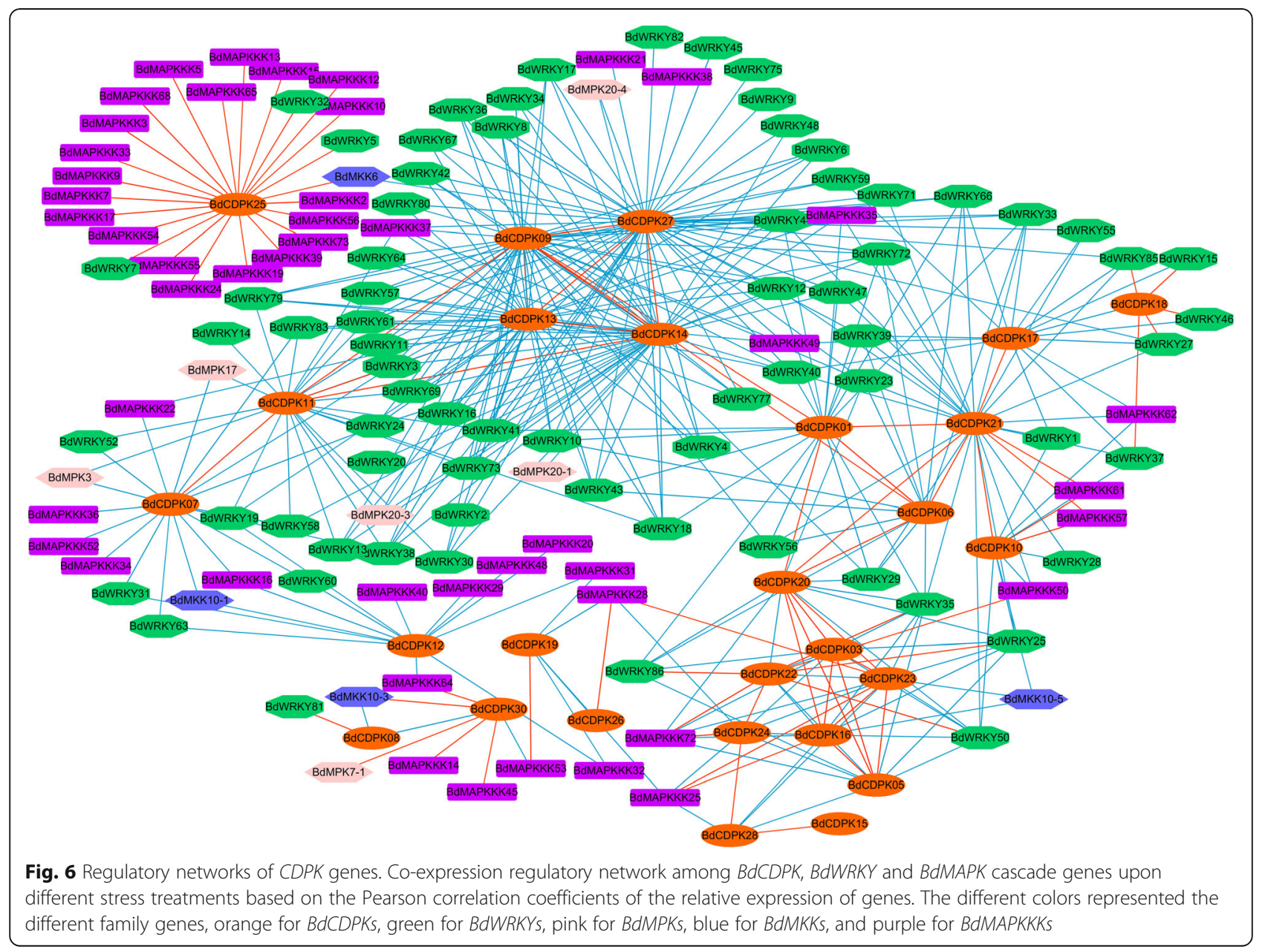


plant tolerance to environmental stresses. In Arabidopsis, Gao et al. found that sustained activation of CPK4, 5, 6, and 11 (subgroup I CDPKs) phosphorylate WRKY transcription factors important for activation of transcriptional reprogramming of immune genes [94]. Consistently, BdCDPK18 and BdCDPK22, members of subgroup I CDPKs, showed a strong co-expression correlation with a set of $B d W R K Y$ transcription factors, implying these BdCDPKs might be involved in WRKY transcription factors mediated stress response signaling network. The diagrammatic co-expression regulatory and predicted PPI network could reveal a deductive signaling pathway of stress response in $B$. distachyon, which showed that the BdCDPKs might act as both the activator and the repressor of WRKYs or MAPK cascade genes to modulate stress response processes. However, the accurate regulatory mechanisms among BdCDPKs, BdWRKYs and BdMAPK cascade of herbaceous plants during development and stress responses required further investigation.

\section{Conclusions}

The identification and systematical study of $C D P K$ genes in $B$. distachyon would help scientist to better explore the functions of CDPKs in integrating $\mathrm{Ca}^{2+}$ signalling pathways in $B$. distachyon in adaptation to vagaries of environments. In this study, 30 members of $B d C D P K$ genes were identified. The gene characterizations and phylogenies have been systematically analyzed. Phylogenetic tree revealed that BdCDPK family members can be clustered into four subgroup (I-IV), based upon sequence homology. And all BdCDPKs were possessed of a typical CDPK structure like AtCPKs, including a variable N-terminal domain, a catalytic Ser/Thr protein kinase domain, an autoinhibitory domain, and a EF-hand domain. However, we found that the structure of EFhands (EF2 and EF4) were shown strong evolutionary divergence compared with CDPKs in Arabidopsis. Synteny results indicated that large number of syntenic relationship events existed between rice and $B$. distachyon, indicating that many consensuses in CDPK protein may have existed before the species divergence between rice and $B$. distachyon. The expression patterns revealed the involvement of $B d C D P K$ genes in various phytohormones and response to abiotic stresses. Moreover, the co-expression and predicted PPI network implied that there was a complex regulatory network between BdCDPKs and BdWRKYs as well as that between BdCDPKs and BdMAPK cascade, and BdCDPKs might be both the activator and the repressor involved in WRKY transcription factors or MAPK cascade mediated stress response processes. Our study provided systematical study of $C D P K$ genes in $B$. distachyon under multiple phytohormones and stresses conditions which is an important step for further investigation the functions of CDPKs across different plant species (Fig. 7).

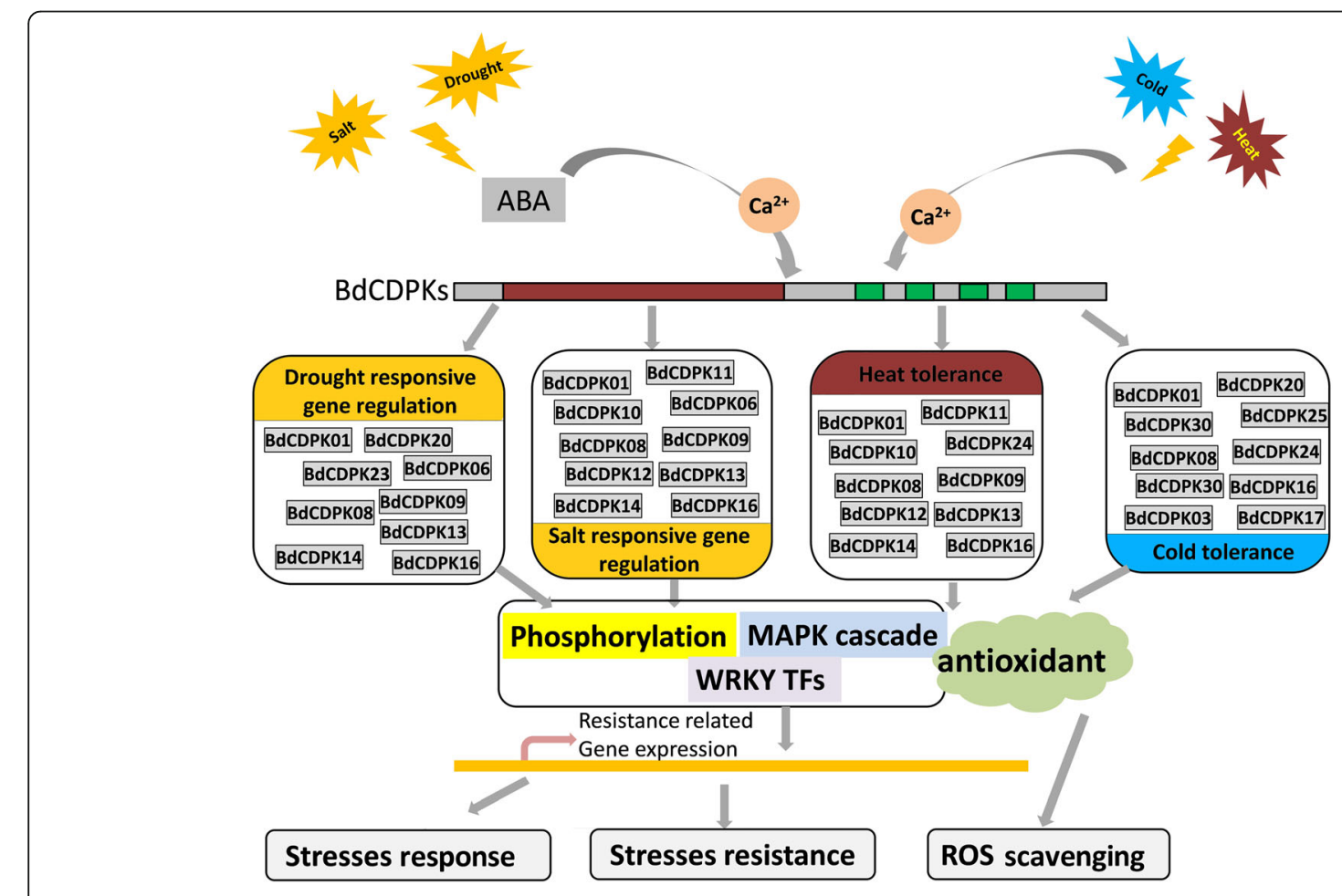

Fig. 7 A summarizing model of BdCDPK function 


\section{Methods \\ Identification and characterization analysis of $B$. distachyon CDPK genes}

All the $B$. distachyon genome sequence data were downloaded from Phytozome V12 (https://phytozome.jgi.doe. gov) [97]. The protein sequences of $A$. thaliana CDPK were obtained from TAIR database (http://www.arabidopsis.org). To identify the CDPK family members in $B$. distachyon, the Arabidopsis and rice CDPK sequences were used as the query to perform a BLASTP search against 52,972 sequences of the protein database of $B$. distachyon, with a cutoff $e$-value $\leq \mathrm{e}^{-10}$. The SMART (http://smart.embl-heidelberg.de/) and InterPro (http:// www.ebi.ac.uk/interpro/) online tools were used to analyze these potential sequences to validate the BLAST search [98]. The theoretical isoelectric point and molecular weight were estimated by $\mathrm{pI} / \mathrm{Mw}$ tool (http:// web.expasy.org/compute_pi), while WoLF PSORT predictor was used to predict the subcellular localization of BdCDPK proteins (https://wolfpsort.hgc.jp). All conserved domains were investigated by multiple alignment analyses using ClustalW, and the phylogenetic analysis for BdCDPKs was performed by using MEGA-X program by the maximum likelihood method, with bootstrap value from 1000 replicates indicated at each node with the following parameters: p-distance and pairwise deletion.

\section{Gene structure and chromosomal locations}

The $B d C D P K$ gene structures were displayed by comparing the coding sequences and corresponding genomic DNA sequences with the Gene Structure Display Server tools (http://gsds.cbi.pku.edu.cn/) [99]. The chromosomal locations of the $B d C D P K$ genes were determined using the $B$. distachyon genome browser, and mapped by using a TBtools toolkit [100]. The Multiple Collinearity Scan toolkit (MCScanX) was used for the synteny analysis, and the result is graphic by Circos software (http:// circos.ca/) [101, 102].

\section{Protein structure and conserved motif analysis}

The MEME program (http://meme-suite.org/) was used to identify the conserved motifs of the $B$. distachyon CDPKs with the following parameters: any number of repetitions of a single motif, the maximum numbers of different motifs up to 15 motifs, the minimum motif width with six amino acids, the maximum motif width of a motif with 80 amino acids [103]. The details of sequence logo of motifs were shown in Additional file 1. The Interpro (www.ebi.ac.uk/interpro) and SMART(smart.embl-heidelberg.de) database were used to identify the conserved domains and important sites in B. distachyon CDPKs [104, 105]. Subsequently, the TBtools toolkit was used to draw the diagram.

\section{Expression analysis of BdCDPKs}

Seeds of $B$. distachyon $\mathrm{Bd} 21$ were germinated on $1 / 2$ Murashige and Skoog medium (MS) solid medium. Seedlings were transferred to soil in temperaturecontrolled $\left(25^{\circ} \mathrm{C}\right)$ growth chambers under a 16-h light/ 8-h dark cycle. The Bd21 seedlings were used for tissuespecific expression analysis and stress or hormone treatments according to previous work with some modifications [106]. For tissue-specific expression analysis, 2week-old seedlings were used to collect the roots, stems and leaves, while 3-month-old seedlings were used to collect the flowers and seeds. For hormone and abiotic stress treatment, 2-week-old seedlings were treated in Murashige and Skoog medium (MS) liquid medium containing $100 \mu \mathrm{M}$ abscisic acid (ABA), $20 \mu \mathrm{M}$ 6benzylaminopurine (6-BA), $5 \mu \mathrm{M}$ 1-naphthylacetic acid (NAA), $10 \mu \mathrm{M}$ gibberellin A3 (GA3), 20\% polyethylene glycol (PEG), $200 \mathrm{mM} \mathrm{NaCl}$ and $10 \mathrm{mM} \mathrm{H}_{2} \mathrm{O}_{2}$ for $3 \mathrm{~h}$, $12 \mathrm{~h}$ and $24 \mathrm{~h}$, respectively. Cold and heat treatments were achieved by placing 2-week-old seedlings in MS liquid medium at $4{ }^{\circ} \mathrm{C}$ or $45^{\circ} \mathrm{C}$ for $3 \mathrm{~h}, 12 \mathrm{~h}$ and $24 \mathrm{~h}$, respectively. Samples were stored at $-80{ }^{\circ} \mathrm{C}$ after liquid nitrogen freezing if not immediately used for RNA isolation and subsequent analysis. Total RNA was extracted by the TRIzol method and treated with DNaseI to eliminate any DNA contamination. First-strand cDNA $(20 \mu \mathrm{L})$ was synthesized according to the instructions for the PrimeScript ${ }^{\mathrm{Tm}}$ RT Master Mix (Takara Biomedical Technology (Beijing) Co., Ltd., Beijing, China). Gene specific primers for quantitative real-time PCR are listed in Additional file 2. The expression of CDPK genes was assessed upon the qPCR result analysis. Each experiment was repeated three biological replications. BdActin (Bradi2g24070) gene was the internal reference gene. For tissue-specific analysis, the average of total $\Delta C$ Tvalue $(\triangle C \mathrm{~T}$. average) was subtracted from all other $\triangle C \mathrm{~T}$ values to obtain second normal standardization, according to the previous method, using the formula: $\mathrm{u}=(\Delta C \mathrm{~T}-\Delta C \mathrm{~T}$. average $) / \sigma$ (in which, $\mathrm{u}$ is the value after normal standardization, and $\sigma$ is the standard deviation) [107]. The $B d C D P K$ gene expression profiles were calculated from the $-\Delta \Delta C \mathrm{~T}$ value $[-\Delta \Delta C \mathrm{~T}=(C$ T control.gene - CTcontrol.actin) - (CTtreat.gene - CTtreat.actin)], and a heatmap was generated by PermutMatrixEN version 1.9.3 software. Two tailed Student's t-test $\left(\mathrm{P}_{0.05}\right)$ was used to determine the significant difference of relative expression of individual $B d C D P K$ genes between control and different treatments (Microsoft Excel 2007). Fold-change greater than 2 with $p$-value of $<0.05$ was defined as up-regulated gene, while a fold change of 0.5 or less was used to define down-regulated genes when the $p$-value of $<0.05$ (Additional file 3). Raw publicly available transcriptome data for $B$. distachyon were downloaded from NCBI GEO and used to analyze the 
expression profiles of $B d C D P K$ genes under diverse stress and hormone conditions (Additional files 4 and 5).

\section{Predicted co-expression and interaction network}

The Pearson correlation coefficients (PCCs) of transcript levels of gene pairs were calculated by Microsoft Excel 2007, based on log2-transformed quantitative Real-Time (qRT)-PCR data. For gene co-regulatory network analysis, the gene pairs, whose PCCs was greater than 0.8 , were selected. Based on the PCCs of these gene pairs, the co-expression networks were represented by using Cytoscape [108]. The predicted protein-protein interaction (PPI) network among BdCDPKs, BdWRKYs and BdMAPK cascade genes was generated by STRING V10.0 software online. The parameters were set as follows: meaning of network edges, confidence; active interaction sources, experiments; minimum required interaction score, 0.8 .

\section{Supplementary information}

Supplementary information accompanies this paper at https://doi.org/10. 1186/s12864-020-6475-6.

Additional file 1 Sequence logos for the conserved motifs of CDPK proteins in B. distachyon.

Additional file $\mathbf{2}$ The list of $\mathrm{qRT}$-PCR primers of $B d C D P K$ genes Additional file $\mathbf{3}$ Expression data of BdCDPK genes after phytohormone treatment and abiotic stresses.

Additional file 4 Expression heatmap of BdCDPK genes under diverse stress and hormone conditions obtained from publicly available transcriptome data.

Additional file 5. List of publicly available transcriptome data accession number.

Additional file $\mathbf{6}$ The CDS and protein sequence of BdCDPKs.

Additional file 7 Phylogenetic relationships among the BdCDPK genes. Gene classes were indicated with different colors.

Additional file $\mathbf{8}$ Conserved domain and important site analysis of CDPKs in B. distachyon.

Additional file 9. Multiple alignments of conserved PDK domain in BdCDPK proteins.

Additional file 10. Multiple alignments of conserved EF domain in BdCDPK proteins.

Additional file 11 Phylogenetic analysis of Arabidopsis, rice and $B$. distachyon CDPKs.

Additional file 12. List of marker genes and qRT-PCR primers of marker genes.

Additional file $\mathbf{1 3}$ Expression of marker genes in B. distachyon in response to phytohormone and abiotic stresses.

Additional file $\mathbf{1 4}$ Homologous gene of BdCDPKs in responsive to hormone and abiotic stress.

Additional file 15 Expression patterns of CDPK, WRKY and MAPK cascade genes in $B$. distachyon in response to abiotic stresses.

Additional file $\mathbf{1 6}$ Predicted protein-protein interaction network of CDPKs, WRKYs and MAPK cascade members identified in B. distachyon.

\section{Acknowledgements}

We want to thank the contributors of the JGl and PlantGDB, which were convenient tools used to search for CDPK genes. We especially appreciate the conversation with the members of our group in developing some of the ideas presented in this study.

\section{Authors' contributions}

$F W$, and $X W$ designed the experiments and organized the manuscript. FW, $F Y, Z X, T L, M J, X L$ and $X W$ performed the experiments. FW, FY and ZX wrote the manuscript. XW, LL and FW edited the manuscript. All the authors discussed the results and contributed to the manuscript. All authors read and approved the final manuscript.

\section{Funding}

This work was supported by National Natural Science Foundation of China [31560075, 31760047, 31960041], Natural Science Foundation of Jiangxi Province [20161BAB214149], and Foundation of Chinese medicine research of health and family planning commission of Jiangxi province [2017B070]. The funding bodies played no role in the design of the study and collection, analysis, and interpretation of data and in writing the manuscript.

\section{Availability of data and materials}

All data generated or analyzed during this study were included in this published article and the Additional files. The sequence data were obtained from Phytozome V12 (https://phytozome.jgi.doe.gov) and TAIR database (http://www.arabidopsis.org)

Ethics approval and consent to participate Not applicable.

\section{Consent for publication}

Not applicable.

\section{Competing interests}

The authors declare that they have no competing interests.

Received: 11 July 2019 Accepted: 9 January 2020

Published online: 16 January 2020

\section{References}

1. Valliyodan B, Nguyen HT. Understanding regulatory networks and engineering for enhanced drought tolerance in plants. Curr Opin Plant Biol. 2006;9(2):189-95.

2. Ranty B, Aldon D, Cotelle V, Galaud JP, Thuleau P, Mazars C. Calcium sensors as key hubs in plant responses to biotic and abiotic stresses. Front Plant Sci. 2016;7:327.

3. Hepler PK. Calcium: a central regulator of plant growth and development. Plant Cell. 2005;17(8):2142-55.

4. Lecourieux D, Ranjeva R, Pugin A. Calcium in plant defence-signalling pathways. New Phytol. 2006:171(2):249-69.

5. Sanders D, Brownlee C, Harper JF. Communicating with calcium. Plant Cell. 1999:11(4):691-706.

6. Hamel LP, Sheen J, Seguin A. Ancient signals: comparative genomics of green plant CDPKs. Trends Plant Sci. 2014;19(2):79-89.

7. Zielinski RE. Calmodulin and Calmodulin-binding proteins in plants. Annu Rev Plant Physiol Plant Mol Biol. 1998:49:697-725.

8. Bouche N, Yellin A, Snedden WA, Fromm H. Plant-specific calmodulinbinding proteins. Annu Rev Plant Biol. 2005;56:435-66.

9. Cheng SH, Willmann MR, Chen HC, Sheen J. Calcium signaling through protein kinases. The Arabidopsis calcium-dependent protein kinase gene family. Plant Physiol. 2002;129(2):469-85.

10. Luan S, Kudla J, Rodriguez-Concepcion M, Yalovsky S, Gruissem W. Calmodulins and calcineurin B-like proteins: calcium sensors for specific signal response coupling in plants. Plant Cell. 2002;14(Suppl):S389-400.

11. Roberts DM, Harmon AC. Calcium-modulated proteins: targets of intracellular calcium signals in higher plants. Annu Rev Plant Physiol Plant Mol Biol. 1992;43:375-414.

12. Boudsocq $M$, Sheen J. CDPKs in immune and stress signaling. Trends Plant Sci. 2013;18(1):30-40

13. Ludwig AA, Romeis T, Jones JD. CDPK-mediated signalling pathways: specificity and cross-talk. J Exp Bot. 2004;55(395):181-8.

14. Harper JF, Harmon A. Plants, symbiosis and parasites: a calcium signalling connection. Nat Rev Mol Cell Biol. 2005;6(7):555-66. 
15. Valmonte GR, Arthur K, Higgins CM, MacDiarmid RM. Calcium-dependent protein kinases in plants: evolution, expression and function. Plant Cell Physiol. 2014;55(3):551-69.

16. Simeunovic A, Mair A, Wurzinger B, Teige M. Know where your clients are: subcellular localization and targets of calcium-dependent protein kinases. Exp Bot. 2016;67(13):3855-72

17. Stael S, Bayer RG, Mehlmer N, Teige M. Protein N-acylation overrides differing targeting signals. FEBS Lett. 2011;585(3):517-22.

18. Hrabak EM, Chan CW, Gribskov M, Harper JF, Choi JH, Halford N, Kudla J, Luan S, Nimmo HG, Sussman MR, et al. The Arabidopsis CDPK-SnRK superfamily of protein kinases. Plant Physiol. 2003;132(2):666-80.

19. Klimecka M, Muszynska G. Structure and functions of plant calciumdependent protein kinases. Acta Biochim Pol. 2007;54(2):219-33.

20. Snedden WA, Fromm H. Calmodulin as a versatile calcium signal transducer in plants. New Phytol. 2001;151:35-66.

21. Ray S, Agarwal P, Arora R, Kapoor S, Tyagi AK. Expression analysis of calcium-dependent protein kinase gene family during reproductive development and abiotic stress conditions in rice (Oryza sativa L. ssp. indica). Mol Genet Genomics. 2007;278(5):493-505.

22. Lanteri ML, Pagnussat GC, Lamattina L. Calcium and calcium-dependent protein kinases are involved in nitric oxide- and auxin-induced adventitious root formation in cucumber. J Exp Bot. 2006;57(6):1341-51.

23. Wei S, Hu W, Deng X, Zhang Y, Liu X, Zhao X, Luo Q, Jin Z, Li Y, Zhou S, et al. A rice calcium-dependent protein kinase OsCPK9 positively regulates drought stress tolerance and spikelet fertility. BMC Plant Biol. 2014;14:133.

24. Matschi S, Werner S, Schulze WX, Legen J, Hilger HH, Romeis T. Function of calcium-dependent protein kinase CPK28 of Arabidopsis thaliana in plant stem elongation and vascular development. Plant J. 2013;73(6):883-96.

25. Myers C, Romanowsky SM, Barron YD, Garg S, Azuse CL, Curran A, Davis RM, Hatton J, Harmon AC, Harper JF. Calcium-dependent protein kinases regulate polarized tip growth in pollen tubes. Plant J. 2009;59(4):528-39.

26. Frattini M, Morello L, Breviario D. Rice calcium-dependent protein kinase isoforms OsCDPK2 and OsCDPK11 show different responses to light and different expression patterns during seed development. Plant Mol Biol. 1999;41(6):753-64.

27. Morello L, Frattini M, Giani S, Christou P, Breviario D. Overexpression of the calcium-dependent protein kinase OsCDPK2 in transgenic rice is repressed by light in leaves and disrupts seed development. Transgenic Res. 2000;9(6): 453-62

28. Zhu SY, Yu XC, Wang XJ, Zhao R, Li Y, Fan RC, Shang Y, Du SY, Wang XF, Wu FQ, et al. Two calcium-dependent protein kinases, CPK4 and CPK11, regulate abscisic acid signal transduction in Arabidopsis. Plant Cell. 2007; 19(10):3019-36

29. Zou JJ, Wei FJ, Wang C, Wu JJ, Ratnasekera D, Liu WX, Wu WH. Arabidopsis calcium-dependent protein kinase CPK10 functions in abscisic acid- and Ca2+-mediated stomatal regulation in response to drought stress. Plant Physiol. 2010;154(3):1232-43.

30. Saijo Y, Hata S, Kyozuka J, Shimamoto K, Izui K. Over-expression of a single Ca2+-dependent protein kinase confers both cold and salt/drought tolerance on rice plants. Plant J. 2000;23(3):319-27.

31. Komatsu S, Yang G, Khan M, Onodera H, Toki S, Yamaguchi M. Overexpression of calcium-dependent protein kinase 13 and calreticulin interacting protein 1 confers cold tolerance on rice plants. Mol Genet Genomics. 2007;277(6):713-23.

32. Almadanim MC, Alexandre BM, Rosa MTG, Sapeta $H$, Leitao AE, Ramalho JC, Lam TT, Negrao S, Abreu IA, Oliveira MM. Rice calcium-dependent protein kinase OsCPK17 targets plasma membrane intrinsic protein and sucrosephosphate synthase and is required for a proper cold stress response. Plant Cell Environ. 2017;40(7):1197-213.

33. Boudsoca M, Willmann MR, McCormack M, Lee H, Shan L, He P, Bush J, Cheng $\mathrm{SH}$, Sheen J. Differential innate immune signalling via $\mathrm{Ca}(2+)$ sensor protein kinases. Nature. 2010:464(7287):418-22.

34. Ma SY, Wu WH. AtCPK23 functions in Arabidopsis responses to drought and salt stresses. Plant Mol Biol. 2007:65(4):511-8.

35. Franz S, Ehlert B, Liese A, Kurth J, Cazale AC, Romeis T. Calcium-dependent protein kinase CPK21 functions in abiotic stress response in Arabidopsis thaliana. Mol Plant. 2011;4(1):83-96

36. Zhao R, Sun HL, Mei C, Wang XJ, Yan L, Liu R, Zhang XF, Wang XF, Zhang DP. The Arabidopsis $\mathrm{Ca}(2+)$-dependent protein kinase CPK12 negatively regulates abscisic acid signaling in seed germination and post-germination growth. New Phytol. 2011;192(1):61-73.
37. Zhao R, Wang XF, Zhang DP. CPK12: a Ca2+-dependent protein kinase balancer in abscisic acid signaling. Plant Signal Behav. 2011;6(11):1687-90.

38. Asano T, Tanaka N, Yang G, Hayashi N, Komatsu S. Genome-wide identification of the rice calcium-dependent protein kinase and its closely related kinase gene families: comprehensive analysis of the CDPKs gene family in rice. Plant Cell Physiol. 2005:46(2):356-66.

39. Li AL, Zhu YF, Tan XM, Wang X, Wei B, Guo HZ, Zhang ZL, Chen XB, Zhao GY, Kong XY, et al. Evolutionary and functional study of the CDPK gene family in wheat (Triticum aestivum L.). Plant Mol Biol. 2008;66(4):429-43.

40. Kong X, LV W, Jiang S, Zhang D, Cai G, Pan J, Li D. Genome-wide identification and expression analysis of calcium-dependent protein kinase in maize. BMC Genomics. 2013;14:433.

41. Liu W, Li W, He Q, Daud MK, Chen J, Zhu S. Genome-wide survey and expression analysis of calcium-dependent protein kinase in Gossypium raimondii. PLoS One. 2014;9(6):e98189.

42. Draper J, Mur LA, Jenkins G, Ghosh-Biswas GC, Bablak P, Hasterok R, Routledge AP. Brachypodium distachyon. A new model system for functional genomics in grasses. Plant Physiol. 2001;127(4):1539-55.

43. Opanowicz M, Vain P, Draper J, Parker D, Doonan JH. Brachypodium distachyon: making hay with a wild grass. Trends Plant Sci. 2008;13(4):172-7.

44. Ozdemir BS, Hernandez P. Filiz E, Budak H. Brachypodium genomics. Int J Plant Genomics. 2008;2008:536104.

45. Liu H, Che Z, Zeng X, Zhou X, Sitoe HM, Wang H, Yu D. Genome-wide analysis of calcium-dependent protein kinases and their expression patterns in response to herbivore and wounding stresses in soybean. Funct Integr Geno. 2016;16(5):481-93.

46. Bender KW, Zielinski RE, Huber SC. Revisiting paradigms of $\mathrm{Ca}(2+)$ signaling protein kinase regulation in plants. Biochemical J. 2018;475(1):207-23.

47. Wang $Q$, Yin X, Chen Q, Xiang N, Sun X, Yang Y, Yang Y. Genome-wide survey indicates diverse physiological roles of the turnip (Brassica rapa var. rapa) calcium-dependent protein kinase genes. Sci Rep. 2017;7(1):15803.

48. Wu J, Wang F, Cheng L, Kong F, Peng Z, Liu S, Yu X, Lu G. Identification, isolation and expression analysis of auxin response factor (ARF) genes in Solanum lycopersicum. Plant Cell Rep. 2011;30(11):2059-73.

49. Xing H, Pudake RN, Guo G, Xing G, Hu Z, Zhang Y, Sun Q, Ni Z. Genomewide identification and expression profiling of auxin response factor (ARF) gene family in maize. BMC Genomics. 2011;12:178.

50. Chang Y, Huang SK, Wang SJ. Coenzyme Q10 inhibits the release of glutamate in rat cerebrocortical nerve terminals by suppression of voltagedependent calcium influx and mitogen-activated protein kinase signaling pathway. J Agric Food Chem. 2012;60(48):11909-18.

51. Fischer $M$, Schreiber $L$, Colby $T$, Kuckenberg $M$, Tacke $E$, Hofferbert HR, Schmidt J, Gebhardt C. Novel candidate genes influencing natural variation in potato tuber cold sweetening identified by comparative proteomics and association mapping. BMC Plant Biol. 2013;13:113.

52. Yang $X$, Tuskan GA, Cheng MZ. Divergence of the Dof gene families in poplar, Arabidopsis, and rice suggests multiple modes of gene evolution after duplication. Plant Physiol. 2006;142(3):820-30

53. Johnson DR, Bhatnagar RS, Knoll LJ, Gordon Jl. Genetic and biochemical studies of protein N-myristoylation. Annu Rev Biochem. 1994;63:869-914.

54. Farazi TA, Waksman G, Gordon Jl. The biology and enzymology of protein N-myristoylation. J Biol Chem. 2001;276(43):39501-4.

55. Martin ML, Busconi L. Membrane localization of a rice calcium-dependent protein kinase (CDPK) is mediated by myristoylation and palmitoylation. Plant J. 2000:24(4):429-35.

56. Mehlmer N, Wurzinger B, Stael S, Hofmann-Rodrigues D, Csaszar E, Pfister B, Bayer $\mathrm{R}$, Teige $\mathrm{M}$. The $\mathrm{Ca}(2+)$-dependent protein kinase CPK3 is required for MAPK-independent salt-stress acclimation in Arabidopsis. Plant J. 2010;63(3): 484-98.

57. Lu SX, Hrabak EM. The myristoylated amino-terminus of an Arabidopsis calcium-dependent protein kinase mediates plasma membrane localization. Plant Mol Biol. 2013:82(3):267-78.

58. Rocks O, Peyker A, Kahms M, Verveer PJ, Koerner C, Lumbierres M, Kuhlmann J, Waldmann H, Wittinghofer A, Bastiaens PI. An acylation cycle regulates localization and activity of palmitoylated Ras isoforms. Science. 2005:307(5716):1746-52.

59. Wang CT, Shao JM. Characterization of the ZmCK1 gene encoding a calcium-dependent protein kinase responsive to multiple abiotic stresses in maize. Plant Mol Biol Report. 2013;31(1):222-30.

60. Chandran V, Stollar EJ, Lindorff-Larsen K, Harper JF, Chazin WJ, Dobson CM, Luisi BF, Christodoulou J. Structure of the regulatory apparatus of a calcium- 
dependent protein kinase (CDPK): a novel mode of calmodulin-target recognition. J Mol Biol. 2006;357(2):400-10.

61. Liese A, Romeis T. Biochemical regulation of in vivo function of plant calcium-dependent protein kinases (CDPK). Biochim Biophys Acta. 2013; 1833(7):1582-9.

62. Zuo R, Hu R, Chai G, Xu M, Qi G, Kong Y, Zhou G. Genome-wide identification, classification, and expression analysis of CDPK and its closely related gene families in poplar (Populus trichocarpa). Mol Biol Rep. 2013: 40(3):2645-62.

63. Shi S, Li S, Asim M, Mao J, Xu D, Ullah Z, Liu G, Wang Q, Liu H. The Arabidopsis Calcium-Dependent Protein Kinases (CDPKs) and Their Roles in Plant Growth Regulation and Abiotic Stress Responses. Int J Mol Sci. 2018; 19(7):1900.

64. Hong Y, Takano M, Liu CM, Gasch A, Chye ML, Chua NH. Expression of three members of the calcium-dependent protein kinase gene family in Arabidopsis thaliana. Plant Mol Biol. 1996;30(6):1259-75.

65. Zhao Y, Pokutta S, Maurer P, Lindt M, Franklin RM, Kappes B. Calciumbinding properties of a calcium-dependent protein kinase from plasmodium falciparum and the significance of individual calcium-binding sites for kinase activation. Biochemistry. 1994;33(12):3714-21.

66. Christodoulou J, Malmendal A, Harper JF, Chazin WJ. Evidence for differing roles for each lobe of the calmodulin-like domain in a calcium-dependent protein kinase. J Biol Chem. 2004;279(28):29092-100.

67. Ludwig AA, Saitoh H, Felix G, Freymark G, Miersch O, Wasternack C, Boller T, Jones JD, Romeis T. Ethylene-mediated cross-talk between calciumdependent protein kinase and MAPK signaling controls stress responses in plants. Proc Natl Acad Sci U S A. 2005;102(30):10736-41.

68. Geiger D, Scherzer S, Mumm P, Marten I, Ache P, Matschi S, Liese A, Wellmann C, Al-Rasheid KA, Grill E, et al. Guard cell anion channel SLAC1 is regulated by CDPK protein kinases with distinct $\mathrm{Ca} 2+$ affinities. Proc Natl Acad Sci U S A. 2010;107(17):8023-8.

69. Abo-el-Saad M, Wu R. A rice membrane calcium-dependent protein kinase is induced by gibberellin. Plant Physiol. 1995;108(2):787-93.

70. Abbasi F, Onodera H, Toki S, Tanaka H, Komatsu S. OsCDPK13, a calciumdependent protein kinase gene from rice, is induced by cold and gibberellin in rice leaf sheath. Plant Mol Biol. 2004;55(4):541-52.

71. Matschi S, Hake K, Herde M, Hause B, Romeis T. The calcium-dependent protein kinase CPK28 regulates development by inducing growth phasespecific, spatially restricted alterations in jasmonic acid levels independent of defense responses in Arabidopsis. Plant Cell. 2015;27(3):591-606.

72. Yoon GM, Cho HS, Ha HJ, Liu JR, Lee HS. Characterization of NtCDPK1, a calcium-dependent protein kinase gene in Nicotiana tabacum, and the activity of its encoded protein. Plant Mol Biol. 1999;39(5):991-1001.

73. Lundberg MS, Curto KA, Bilato C, Monticone RE, Crow MT. Regulation of vascular smooth muscle migration by mitogen-activated protein kinase and calcium/calmodulin-dependent protein kinase II signaling pathways. J Mol Cell Cardiol. 1998;30(11):2377-89.

74. Choi HI, Park HJ, Park JH, Kim S, Im MY, Seo HH, Kim YW, Hwang I, Kim SY. Arabidopsis calcium-dependent protein kinase AtCPK32 interacts with ABF4, a transcriptional regulator of abscisic acid-responsive gene expression, and modulates its activity. Plant Physiol. 2005;139(4):1750-61.

75. Kavanagh BD, Dent P, Schmidt-Ullrich RK, Chen P, Mikkelsen RB. Calciumdependent stimulation of mitogen-activated protein kinase activity in A431 cells by low doses of ionizing radiation. Radiat Res. 1998;149(6):579-87.

76. Kakei Y, Mochida K, Sakurai T, Yoshida T, Shinozaki K, Shimada Y Transcriptome analysis of hormone-induced gene expression in Brachypodium distachyon. Sci Rep. 2015;5:14476.

77. Zhang F, Wei Q, Shi J, Jin X, He Y, Zhang Y, Luo Q, Wang Y, Chang J, Yang $G$, et al. Brachypodium distachyon BdPP2CA6 interacts with BdPYLs and BdSnRK2 and positively regulates salt tolerance in transgenic Arabidopsis. Front Plant Sci. 2017;8:264.

78. Niu X, Chen S, Li J, Liu Y, Ji W, Li H. Genome-wide identification of GRAS genes in Brachypodium distachyon and functional characterization of BdSLR1 and BdSLRL1. BMC Genomics. 2019;20(1):635

79. Chen F, Fasoli M, Tornielli GB, Dal Santo S, Pezzotti M, Zhang L, Cai B, Cheng ZM. The evolutionary history and diverse physiological roles of the grapevine calcium-dependent protein kinase gene family. PLoS One. 2013; 8(12):e80818.

80. Huang K, Peng L, Liu Y, Yao R, Liu Z, Li X, Yang Y, Wang J. Arabidopsis calcium-dependent protein kinase AtCPK1 plays a positive role in salt/ drought-stress response. Biochem Biophys Res Commun. 2018;498(1):92-8.
81. Coca M, San Segundo B. AtCPK1 calcium-dependent protein kinase mediates pathogen resistance in Arabidopsis. Plant J. 2010;63(3):526-40.

82. Wan B, Lin Y, Mou T. Expression of rice $\mathrm{Ca}(2+)$-dependent protein kinases (CDPKs) genes under different environmental stresses. FEBS Lett. 2007; 581(6):1179-89

83. Almadanim MC, Goncalves NM, Rosa MTG, Alexandre BM, Cordeiro AM, Rodrigues M, Saibo NJM, Soares CM, Romao CV, Oliveira MM, et al. The rice cold-responsive calcium-dependent protein kinase OsCPK17 is regulated by alternative splicing and post-translational modifications Biochimica et biophysica acta Molecular cell research. 2018;1865(2):23146.

84. Chen $L$, Ren F, Zhong $H$, Feng $Y$, Jiang $W$, Li X. Identification and expression analysis of genes in response to high-salinity and drought stresses in Brassica napus. Acta Biochim Biophys Sin. 2010;42(2):154-64.

85. Ryu JY, Hong SY, Jo SH, Woo JC, Lee S, Park CM. Molecular and functional characterization of cold-responsive C-repeat binding factors from Brachypodium distachyon. BMC Plant Biol. 2014;14:15.

86. Wen F, Wu X, Li T, Jia M, Liu X, Li P, Zhou X, Ji X, Yue X. Genome-wide survey of heat shock factors and heat shock protein 70 s and their regulatory network under abiotic stresses in Brachypodium distachyon. PLoS One. 2017;12(7):e0180352.

87. Shigeoka S, Ishikawa T, Tamoi M, Miyagawa Y, Takeda T, Yabuta Y, Yoshimura K. Regulation and function of ascorbate peroxidase isoenzymes. J Exp Bot. 2002;53(372):1305-19.

88. Dubrovina AS, Kiselev KV, Khristenko VS. Expression of calcium-dependent protein kinase (CDPK) genes under abiotic stress conditions in wild-growing grapevine Vitis amurensis. J Plant Physiol. 2013;170(17):1491-500.

89. Urao T, Katagiri T, Mizoguchi T, Yamaguchi-Shinozaki K, Hayashida N, Shinozaki K. Two genes that encode $\mathrm{Ca}(2+)$-dependent protein kinases are induced by drought and high-salt stresses in Arabidopsis thaliana. Mol Gen Genet. 1994;244(4):331-40.

90. Xu J, Tian YS, Peng RH, Xiong AS, Zhu B, Jin XF, Gao F, Fu XY, Hou XL, Yao $\mathrm{QH}$. AtCPK6, a functionally redundant and positive regulator involved in salt/drought stress tolerance in Arabidopsis. Planta. 2010;231(6):1251-60.

91. Bundo M, Coca M. Calcium-dependent protein kinase OsCPK10 mediates both drought tolerance and blast disease resistance in rice plants. J Exp Bot. 2017;68(11):2963-75

92. Wang JP, XU YP, Munyampundu JP, Liu TY, Cai XZ. Calcium-dependent protein kinase (CDPK) and CDPK-related kinase (CRK) gene families in tomato: genome-wide identification and functional analyses in disease resistance. Mol Genet Genomic. 2016;291(2):661-76.

93. Xu X, Liu M, Lu L, He M, Qu W, Xu Q, Qi X, Chen X. Genome-wide analysis and expression of the calcium-dependent protein kinase gene family in cucumber. Mol Genet Genomics. 2015;290(4):1403-14.

94. Gao X, Chen X, Lin W, Chen S, Lu D, Niu Y, Li L, Cheng C, McCormack M, Sheen J, et al. Bifurcation of Arabidopsis NLR immune signaling via $\mathrm{Ca}(2)(+$ )-dependent protein kinases. PLoS Pathog. 2013;9(1):e1003127.

95. Wurzinger B, Mair A, Pfister B, Teige M. Cross-talk of calcium-dependent protein kinase and MAP kinase signaling. Plant Signal Behav. 2011;6(1):8-12.

96. Xie K, Chen J, Wang Q, Yang Y. Direct phosphorylation and activation of a mitogen-activated protein kinase by a calcium-dependent protein kinase in rice. Plant Cell. 2014;26(7):3077-89.

97. Goodstein DM, Shu S, Howson R, Neupane R, Hayes RD, Fazo J, Mitros T, Dirks W, Hellsten U, Putnam N, et al. Phytozome: a comparative platform for green plant genomics. Nucleic Acids Res. 2012;40(Database issue):D1178-86.

98. Ludwig-Muller J. Auxin conjugates: their role for plant development and in the evolution of land plants. J Exp Bot. 2011;62(6):1757-73.

99. Hu B, Jin J, Guo AY, Zhang H, Luo J, Gao G. GSDS 2.0: an upgraded gene feature visualization server. Bioinformatics. 2015;31(8):1296-7.

100. Chen C, Xia R, Chen H, He Y. TBtools, a Toolkit for Biologists integrating various HTS-data handling tools with a user-friendly interface. bioRxiv. 2018; 289660

101. Wang Y, Tang H, Debarry JD, Tan X, Li J, Wang X, Lee TH, Jin H, Marler B, Guo H, et al. MCScanX: a toolkit for detection and evolutionary analysis of gene synteny and collinearity. Nucleic Acids Res. 2012;40(7):e49.

102. Krzywinski M, Schein J, Birol I, Connors J, Gascoyne R, Horsman D, Jones SJ, Marra MA. Circos: an information aesthetic for comparative genomics. Genome Res. 2009;19(9):1639-45.

103. Bailey TL, Williams N, Misleh C, Li WW. MEME: discovering and analyzing DNA and protein sequence motifs. Nucleic acids Res. 2006;34(Web Server issue):W369-73, 
104. Marchler-Bauer A, Bo Y, Han L, He J, Lanczycki CJ, Lu S, Chitsaz F, Derbyshire MK, Geer RC, Gonzales NR, et al. CDD/SPARCLE: functional classification of proteins via subfamily domain architectures. Nucleic Acids Res. 2017;45(D1): D200-3.

105. Letunic I, Bork P. 20 years of the SMART protein domain annotation resource. Nucleic Acids Res. 2018;46(D1):D493-6.

106. Wen F, Zhu H, Li P, Jiang M, Mao W, Ong C, Chu Z. Genome-wide evolutionary characterization and expression analyses of WRKY family genes in Brachypodium distachyon. DNA Res. 2014;21(3):327-39.

107. Sun R, Wang K, Guo T, Jones DC, Cobb J, Zhang B, Wang Q. Genome-wide identification of auxin response factor (ARF) genes and its tissue-specific prominent expression in Gossypium raimondii. Funct Integr Genomics. 2015;15(4):481-93.

108. Shannon P, Markiel A, Ozier O, Baliga NS, Wang JT, Ramage D, Amin N, Schwikowski B, Ideker T. Cytoscape: a software environment for integrated models of biomolecular interaction networks. Genome Res. 2003;13(11): 2498-504.

\section{Publisher's Note}

Springer Nature remains neutral with regard to jurisdictional claims in published maps and institutional affiliations.

\section{Ready to submit your research? Choose BMC and benefit from:}

- fast, convenient online submission

- thorough peer review by experienced researchers in your field

- rapid publication on acceptance

- support for research data, including large and complex data types

- gold Open Access which fosters wider collaboration and increased citations

- maximum visibility for your research: over $100 \mathrm{M}$ website views per year

At $\mathrm{BMC}$, research is always in progress.

Learn more biomedcentral.com/submissions 